\title{
Diagnosis, prognosis and treatment of primary central nervous system lymphoma in the elderly population (Review)
}

\author{
YANXIA LIU, QINGMIN YAO and FENG ZHANG \\ Department of Hematology, Shandong Provincial Hospital Affiliated to Shandong First Medical University, \\ Jinan, Shandong 250021, P.R. China
}

Received October 20, 2020; Accepted January 18, 2021

DOI: 10.3892/ijo.2021.5180

\begin{abstract}
Primary central nervous system lymphoma (PCNSL) is a rare subtype of extranodal non-Hodgkin lymphoma that is unique and different from systemic diffuse large B-cell lymphomas. The median age at diagnosis of PCNSL is 65 years and its incidence is rising rapidly in the elderly population. A total of $\geq 20 \%$ of all patients with PCNSL are $\geq 80$ years old. Notably, age has been identified as an independent poor prognostic factor for PCNSL. Elderly patients have an inferior prognosis to that of younger patients and are more severely affected by iatrogenic toxicity; therefore, elderly patients represent a unique and vulnerable treatment subgroup. The present review summarized the available literature to provide an improved understanding of the epidemiology, clinical characteristics, diagnosis, prognosis and management of PCNSL in the elderly population. Notably, the incidence of PCNSL in immunocompetent elderly patients, predominantly in men, is increasing. For the diagnosis of CNSL, imaging-guided stereotactic biopsy is considered the gold standard. When stereotactic biopsy is not possible or conclusive, certain biomarkers have been described that can help establish a diagnosis. PCNSL has a very poor prognosis in the elderly, even though several prognostic scoring systems exist and several prognostic markers have been reported in patients with PCNSL. Furthermore, the treatment of elderly patients remains challenging; it is unlikely that a novel agent could be used as a curative monotherapy; however, a combination of novel agents with polychemotherapy or its combination with other novel drugs may have therapeutic potential.
\end{abstract}

\section{Introduction}

Primary central nervous system (CNS) lymphoma (PCNSL) is a rare subtype of extranodal non-Hodgkin lymphoma

Correspondence to: Dr Feng Zhang, Department of Hematology, Shandong Provincial Hospital Affiliated to Shandong First Medical University, 324 Jingwu Road, Jinan, Shandong 250021, P.R. China E-mail: zhangfengjn@163.com

Key words: primary central nervous system lymphoma, diagnosis, prognosis, treatment
(NHL), which is typically confined to the brain, spinal cord, eyes or leptomeninges, without evidence of systemic spread. PCNSL was first described by Bailey in 1929 as perivascular sarcoma (1). The symptoms of PCNSL often progress rapidly and are non-specific and vary depending mainly on the primary location of the lesions. Contrast-enhanced brain MRI is the preferred method of diagnosis (2), and the histological analysis of biopsy material, usually obtained by imaging-guided stereotactic biopsy, is regarded as the gold standard for the diagnosis of PCNSL (3). In total, 95\% of PCNSL cases worldwide are classified histologically as diffuse large B-cell lymphomas (DLBCL); however, PCNSL is unique and distinct from systemic DLBCL $(4,5)$. Considering the recent identification of distinct genotypic and immunophenotypic features, with reference to morphological and clinical characteristics, primary DLBCL of the CNS (PCNS-DLBCL) has been classified as a specific lymphoma subtype in the World Health Organization lymphoma classification system since 2008 (6). Since the majority of PCNSL cases are DLBCL and other pathological types are very rare, PCNS-DLBCL and PCNSL are almost the same concept. The median age at diagnosis of PCNSL is 65 years and the incidence is rising rapidly in the elderly population $(7,8)$. Patients $>60$ years old account for $>50 \%$ of all PCNSL cases and up to $20 \%$ of all patients with PCNSL are aged $\geq 80$ years (2). Notably, age has been identified as an independent poor prognostic factor for PCNSL (9). For PCNSL, two major scoring systems have been established and are widely used. Elderly patients have an inferior prognosis compared with that of younger patients and are more severely affected by iatrogenic toxicity; therefore, they represent a unique and vulnerable treatment subgroup $(10,11)$. There is an unmet clinical need to define optimal treatment for this population. In the present review, the available literature has been reviewed to provide an improved understanding of the epidemiology, clinical characteristics, diagnosis, prognosis and management of PCNSL in the elderly; the present review focused on the recent advances in prognosis and treatment.

\section{Contents}

1. Epidemiology

2. Clinical manifestation

3. Brain imaging 
4. Pathology

5. Diagnosis

6. Prognosis

7. Treatment

8. Conclusion

\section{Epidemiology}

PCNSL accounts for $\sim 4 \%$ of all intracranial malignancies, $5 \%$ of all extranodal lymphomas and $<1 \%$ of all NHL (12). The incidence rate for PCNSL worldwide is 0.47 per 100,000 people per year, occurring mostly in the 6th decade of life, with a male:female ratio of 1.2:1.7 $(7,13,14)$. Moreover, a rising incidence has been observed in patients aged $>60$ years in the last 10 years, with patients aged 70-79 years old having the highest incidence (15). Notably, African-American individuals tend to present with PCNSL at a younger age ( $<50$ years), whereas Caucasian individuals usually present with the disease when $>50$ years old $(7)$.

PCNSL can affect immunocompetent and immunocompromised patients. Most cases occur sporadically; however, a compromised immune system, both primary and acquired, has been reported to be a predisposing factor for PCNSL (16). The risk of PCNSL has also been reported to be $2-6 \%$ in patients with AIDS and 1-5\% in those that have received organ transplants (13). Primary immunodeficiency has been reported to confer a $4 \%$ risk of developing PCNSL. In addition, the incidence of PCNSL has been shown to be inversely correlated with CD4 cell counts (17) and has declined in HIV-infected individuals since the widespread use of highly active antiretroviral therapy $(7,18)$. Currently, immunocompetent patients represent the vast majority of patients with PCNSL (19); in addition, these patients are often diagnosed between the ages of 50 and 70 years, whereas immunocompromised patients often present with the disease earlier in life, in their 30s and 40s (20).

\section{Clinical manifestation}

The clinical manifestation of PCNSL varies depending mainly on the primary location of the lesions. The symptoms often progress rapidly and are non-specific. The most common presentation is focal neurological symptoms, which have been observed in $70 \%$ of patients (21). In addition, a total of $43 \%$ of patients presented with neuropsychiatric symptoms, followed by signs of increased intracranial pressure, such as headache and vomiting in $33 \%$, seizures in $14 \%$ and ocular symptoms in $4 \%$ of cases (21). In addition, 'B symptoms', such as weight loss, fever and night sweats have been reported to be rare in PCNSL (21) (Fig. 1).

\section{Brain imaging}

PCNSL nearly always exhibits significant contrast uniform enhancement, with or without necrosis, on computed tomography (CT) and magnetic resonance imaging (MRI) scans (21). Furthermore, linear enhancement along perivascular spaces is highly characteristic of PCNSL (22). On a CT scan, PCNSL in immunocompetent individuals often presents as a single hyper- or iso-attenuated lesion. On an MRI scan, PCNSL is typically iso-hypointense on T1-weighted imaging and iso-hypointense to gray matter on T2-weighted imaging; in a previous study, in $85 \%$ of patients, a strong homogeneous pattern of enhancement was detected, due to its hypercellularity (21). However, PCNSL lesions may be non-contrast-enhancing, and can contain atypical features of hemorrhage, calcification, cysts and necrosis (23).

Lesions are often centrally located within cerebral white matter, and are often found in the periventricular region. A total of $87 \%$ of PCNSL lesions were previously reported to be supratentorial, with $39 \%$ of them having frontoparietal involvement in a retrospective analysis from French and Belgian medical centers (12). A total of $9-25 \%$ of newly diagnosed PCNSL were also demonstrated to have cerebellar involvement $(24,25)$. Malikova et al (26) demonstrated that parenchymal involvement was much more common than previously hypothesized. Leptomeningeal lesions of CNSL often involve the cranial nerves, subependymal regions spinal cord or spinal nerve roots, whereas dural involvement is rare in PCNSL or secondary CNSL (22).

While immunocompetent patients usually have solitary lesions with homogenous enhancement, $20-40 \%$ of cases have been reported to present with multiple lesions, and up to $13 \%$ with ring-like enhancement (27). The typical appearance of PCNSL in patients with immunodeficiency is different from that in immunocompetent patients. A total of $30-80 \%$ of immunodeficient patients have been shown to present with multiple lesions that usually have necrosis, resulting in an irregular ring-enhancing pattern and a higher propensity for spontaneous hemorrhage (27).

\section{Pathology}

Notably, $295 \%$ of PCNSL cases are classified histologically as DLBCL, and $5 \%$ as other histologies, including T-cell, Burkitt, lymphoblastic and marginal zone lymphomas (28). Gene expression profiling has been used to establish three major DLBCL subtypes: Germinal center B-cell-like (GCB), activated $\mathrm{B}$-cell-like (ABC) and type 3. The type 3 subgroup is not well defined, but the type 3 and $\mathrm{ABC}$ subtypes appear to have a poor outcome and are often grouped together as non-germinal center (non-GC) subtype (29). Further genomic sequencing revealed that the pattern of somatic mutations in DLBCL was classified as GCB tumors and non-GC tumors depending on the cell of origin. GCB tumors were revealed to more likely have mutations in EZH2 and GNA13, and translocations in bcl-2. Non-GC tumors were associated with mutations in MyD88, CD79B, CARD11 and TNFAIP3, all of which are involved in B-cell receptor (BCR) signaling activating $N F-\kappa B(30)$. Tumors can be subdivided into GCB and non-GC types based on the expression pattern of CD10, bcl-6 and MUM-1/IRF4. Staining of PCNSL biopsies to distinguish these DLBCL subgroups $\left(\mathrm{CD}^{-} 0^{-}\right.$, bcl- $\left.6^{+}, \mathrm{MUM}-1 / \mathrm{IRF}^{+}\right)$showed that the vast majority $(>80 \%)$ of PCNSL-DLBCLs were the non-GC immunophenotype (31). To the best of our knowledge, age-related pathological characteristics in PCNSL tumor tissue have not been identified. 


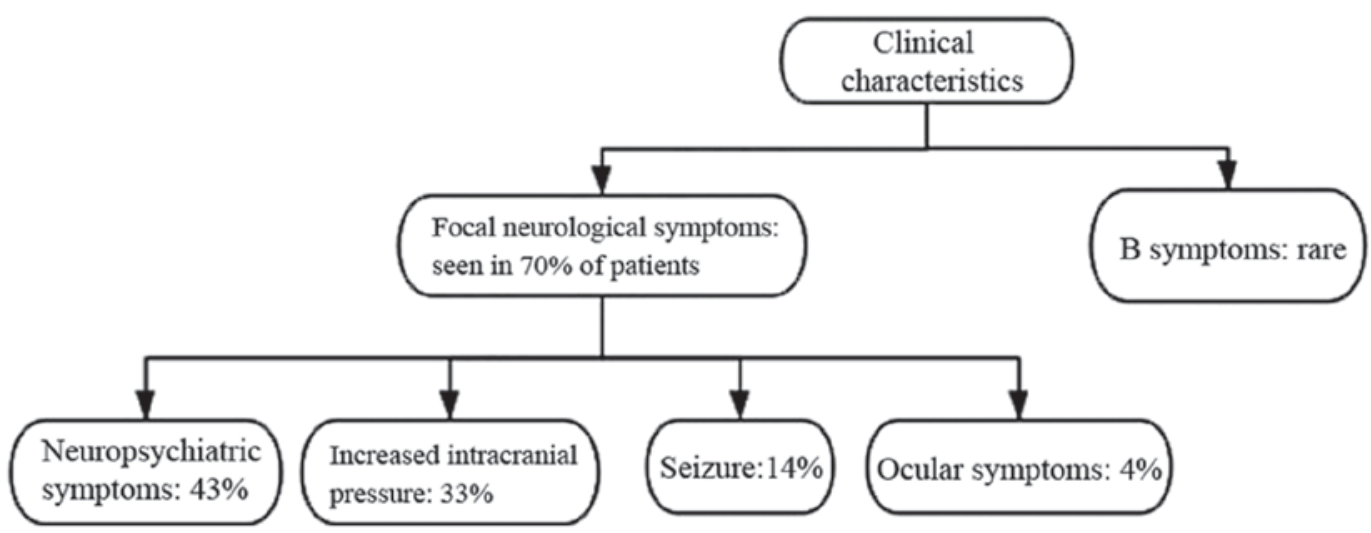

Figure 1. Clinical characteristics of PCNSL. PCNSL, primary central nervous system lymphoma.

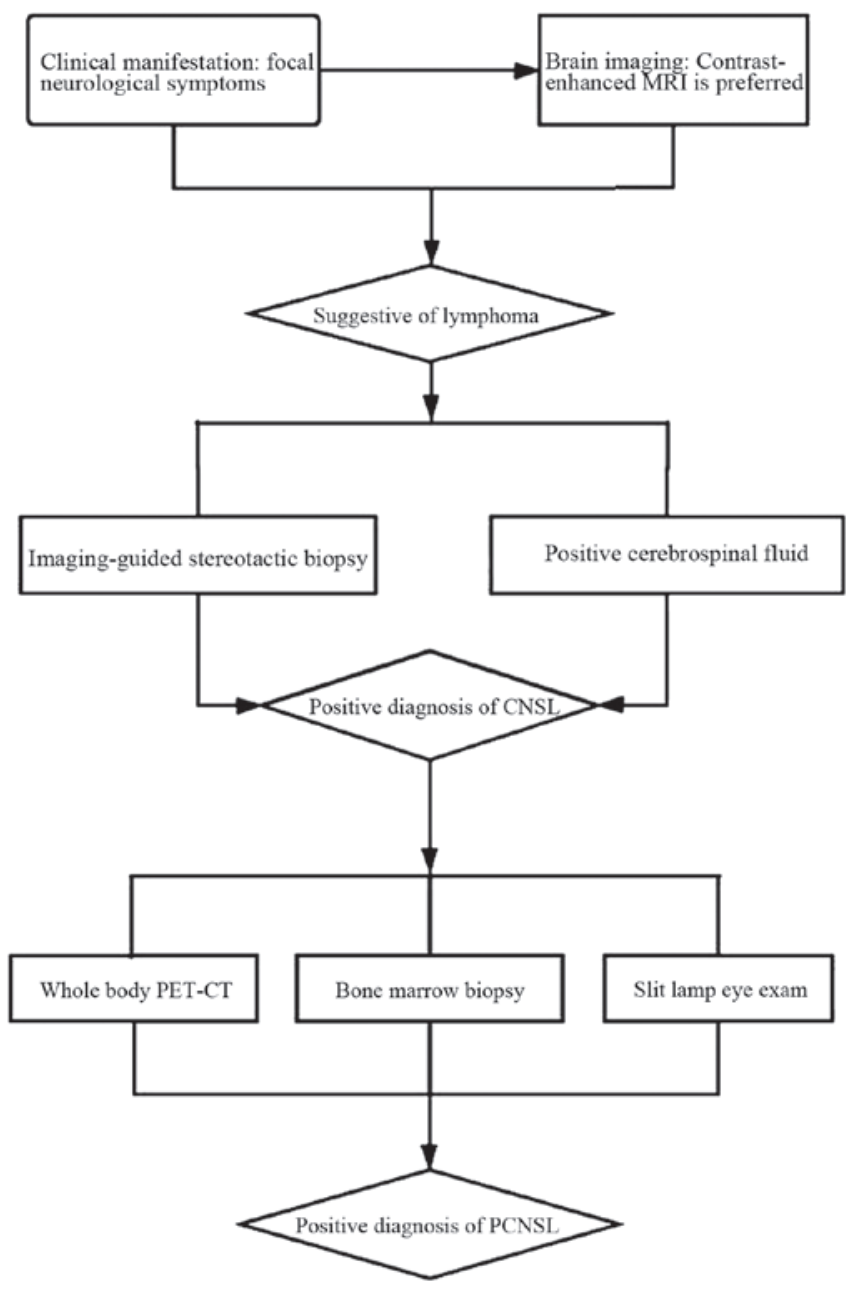

Figure 2. Diagnosis of PCNSL. MRI, magnetic resonance imaging; PET-CT, positron emission tomography-computed tomography; PCNSL, primary central nervous system lymphoma.

\section{Diagnosis}

PCNSL typically presents as an intracranial mass lesion, alongside a combination of generalized symptoms, including headaches, confusion and lethargy, and lateralizing symptoms, such as hemiparesis. Focal neurological deficits have been reported to affect $50 \%$ of patients, and PCNSL is usually misdiagnosed early as a cerebrovascular disorder (2). Contrast-enhanced brain MRI scan is the preferred method of diagnosis (2). Definitive diagnosis requires pathological confirmation. For the diagnosis of CNSL, histological analysis of biopsy material, usually obtained by imaging-guided stereotactic biopsy, is regarded as the gold standard (3). An early brain biopsy when CNSL is suspected is considered a valid option to reduce diagnostic delay, with a high rate of definitive diagnosis and a low complication rate (24). A positive cerebrospinal fluid (CSF) test for lymphoma, referring to the presence of lymphoma cells in CSF by flow cytometry and cytology, can obviate the need for a surgical procedure (32). For the diagnosis of PCNSL, a body positron emission tomography-computed tomography scan, bone marrow biopsy and slit lamp eye exam should be performed to exclude extraneural disease (Fig. 2).

Notably, PCNSL is sensitive to corticosteroids, and pathological evaluation of corticosteroid-pretreated PCNSL has been shown to lead to a final diagnosis in only 50-85\% of cases (33). Sensitivity may also be significantly reduced when tissue is obtained through a stereotactic biopsy after the patients were treated with corticosteroids (24). Therefore, corticosteroids should be avoided prior to biopsy as much as possible, in order to decrease their impact on diagnosis.

When stereotactic biopsy is not possible or conclusive, certain biomarkers have been shown to help establish the diagnosis of CNSL (Table I). In HIV-positive patients with CNSL, Epstein-Barr virus (EBV) DNA in the CSF may be used as a diagnostic biomarker (34). In HIV-negative patients, several diagnostic biomarkers, including interleukin (IL)-10, IL-6, CXC chemokine ligand-13 (CXCL13), neopterin, $\beta 2$-microglobulin ( $\beta 2-\mathrm{MG})$, osteopontin, soluble CD27, specific microRNAs and cell-free DNA, have been described (35-45). Soluble transmembrane activator and CAML interactor, and soluble B-cell maturation antigen in the CSF have also been identified as promising novel biomarkers for the diagnosis and treatment monitoring of PCNSL (46). In addition, a proliferation-inducing ligand, alone or in combination with B-cell activating factor, in the CSF may serve as a diagnostic biomarker for patients with CNSL (3). Furthermore, next-generation sequencing of circulating tumor DNA isolated from CSF samples may provide a promising diagnostic biomarker (47). Moreover, in recent years the 
Table I. Diagnostic biomarkers associated with primary central nervous system lymphoma.

A, In HIV-positive patients

\begin{tabular}{lcc}
\hline First author, year & Biomarkers & (Refs.) \\
\hline Antinori, 1999 & EBV DNA in the CSF & (34) \\
\hline
\end{tabular}

B, In HIV-negative patients

\begin{tabular}{lll}
\hline First author, year & \multicolumn{1}{c}{ Biomarkers } & (Refs.) \\
\hline Sasagawa, 2015 & IL-10 & $(35)$ \\
Song, 2016 & IL-6 & $(36)$ \\
Rubenstein, 2013 & CXCL13 & $(37)$ \\
Viaccoz, 2015 & Neopterin & $(38)$ \\
Caudie, 2005 & 32-MG & $(39)$ \\
Strehlow, 2016 & Osteopontin \\
Kersten, 1996 & sCD27 \\
Baraniskin, 2011 & Specific microRNAs \\
Rimelen, 2019 & Cell-free DNA \\
Thaler, 2017 & sTACI and sBCMA in the \\
Mulazzani, 2019 & CSF & APRIL alone or in \\
& combination with BAFF & $(46)$ \\
Ho, 2019 & in the CSF \\
Deguchi, 2019 & Next-generation sequencing \\
\hline
\end{tabular}

EBV, Epstein-Barr virus; CSF, cerebrospinal fluid; IL, interleukin; CXCL, CXC chemokine Ligand; $\beta 2-\mathrm{MG}, \beta 2$-microglobulin; sTACI, soluble transmembrane activator and CAML interactor; sBCMA, soluble B-cell maturation antigen; APRIL, a proliferation-inducing ligand; BAFF, B-cell activating factor; ctDNA, circulating tumor DNA; SWI, susceptibility-weighted imaging.

clinical significance of susceptibility-weighted imaging has been established in the differential diagnosis of PCNSL (48).

\section{Prognosis}

PCNS-DLBCL is an aggressive malignancy that has been reported to be associated with an overall survival (OS) of 12-18 months $(28,49,50)$. Without treatment, OS has been shown to decrease to 1.5-3.3 months (51). Since the introduction of high-dose (HD)-methotrexate (MTX)-based chemotherapy regimens, OS has increased substantially; it has been reported to be 16.3-66 months with a 2-year OS rate of 42-80.8\% (52-56).

Outcomes for patients aged $>60$ years remain poor, with 1-year progression-free survival (PFS) rates being reported at $\sim 40 \%$ and a median OS in the range of $8-43$ months in elderly patients receiving multi-drug regimens, including HD-MTX (57-63). Until now, only a few randomized controlled trials (10,59-65) dedicated to treating PCNSL in the elderly population have been performed (Table II). An epidemiological analysis demonstrated that, while the median OS of all patients with PCNSL doubled, from 12.5 months in the 1970s to 26 months in the 2010 s, this progress was restricted to young patients. Conversely, the median OS of patients with PCNSL aged $\geq 70$ years has not improved in $>40$ years ( 6 months in the 1970 s vs. 7 months in the 2010s) (66). Furthermore, patients aged $>70$ years have been excluded from several clinical trials; it has been reported that $\sim 1 / 4$ of patients aged $>70$ years with PCNSL who survive for $>3$ months from diagnosis do not receive chemotherapy at all in the US (53). Notably, in a previous study, the fraction of patients who were not treated with chemotherapy increased from 14 to 23 , and to $44 \%$ in the of 61-70, 71-80 and >80 years age groups, respectively (2). Therefore, the treatment of PCNSL, particularly in elderly patients, remains challenging.

Although PCNSL is a significantly chemosensitive neoplasm, often achieving complete response (CR) after initial treatment, $30-50 \%$ of patients may not benefit from this intensive treatment due to old age, delayed neurotoxicity, drug resistance or relapse $(67,68)$. Despite advances in induction and consolidation regimens, relapse has been observed in $35-60 \%$ of patients 2 years after the initial diagnosis, and in $4 \%$ of patients 5 years after the initial diagnosis (69). In a large population-based study, overall prognosis was found to be poor following salvage therapy, with the median PFS and OS following recurrence at 2.2 and 3.5 months, respectively, with elderly patients having the worse outcome (67). In addition, $\sim 1 / 3$ of the patients with PCNSL had primary refractory disease, that is, they failed to respond to the first-line treatment (32). In a French prospective cohort, refractory patients were found to have a poor prognosis (median OS, 2.1 months) (68). Despite the development of novel and intensified therapeutic regimens, PCNSL has a very poor prognosis and its incidence in people aged $\geq 65$ years is increasing in the US (8).

For PCNSL, two major scoring systems have been established and are widely used. The Memorial Sloan-Kettering Cancer Center prognostic model describes three groups, based on age and Karnofsky performance score (KPS; Table III). The most relevant are poor performance status and advanced age. Patients aged $>50$ years with a KPS of $<70$ have been reported to have the worst prognosis, with a median survival of 1.1 years (70). The International Extranodal Lymphoma Study Group (IELSG) described five prognostic factors as independent predictors of poor prognosis with a low OS (Table IV). Each factor was set at 1 point. According to the degree of integration, they were divided into three groups, 0-1, 2-3 and 4-5. The 2-year survival of patients with $0-1,2-3$ or $4-5$ of these unfavorable factors was 80,48 and $15 \%$, respectively (71).

Although the aforementioned two prognostic scoring systems already exist, risk assessment at the time of diagnosis remains unsatisfactory. Several prognostic markers have been reported in patients with PCNSL (Table V).

Gross total resection following surgery is a significant independent favorable prognostic marker for OS (72). The completion of three cycles of HD-MTX chemotherapy was also found to be a significant independent prognostic factor for patient survival (73). In a previous study, patients with CR following initial HD-MTX had a longer survival time (74). CR status following HD chemotherapy with autologous stem cell 
Table II. Summary of randomized controlled trial research to treat primary central nervous system lymphoma in the elderly.

\begin{tabular}{|c|c|c|c|c|c|c|c|}
\hline $\begin{array}{l}\text { First author, } \\
\text { year }\end{array}$ & Treatment protocol & Phase & $\begin{array}{c}\text { Patients, } \\
\mathrm{n}\end{array}$ & $\begin{array}{l}\text { Median } \\
\text { age, years }\end{array}$ & $\begin{array}{l}\text { Median OS, } \\
\text { months or } \%\end{array}$ & $\begin{array}{l}\text { Median PFS, } \\
\text { months or } \%\end{array}$ & (Refs.) \\
\hline Omuro, 2007 & HD-MTX + TMZ & II & 23 & 68 & 35 & 8 & $(10)$ \\
\hline Fritsch, 2017 & $\begin{array}{l}\mathrm{R}+\mathrm{HD}-\mathrm{MTX}+\text { procarbazine }+ \\
\text { lomustine }(\mathrm{R}-\mathrm{MPL}) / \mathrm{RMP} \rightarrow \\
\text { procarbazine maintenance }\end{array}$ & II & 107 & 73 & $\begin{array}{c}\text { 2-year OS } \\
47 \%\end{array}$ & $\begin{array}{c}\text { 2-year PFS } \\
37.3 \%\end{array}$ & (59) \\
\hline $\begin{array}{l}\text { Hoang-Xuan, } \\
2003\end{array}$ & $\begin{array}{l}\text { HD-MTX + lomustine + } \\
\text { procarbazine }+ \\
\text { methylprednisolone }+ \\
\text { IT MTX and cytarabine }\end{array}$ & II & 50 & 72 & 14.3 & $\begin{array}{c}1 \text {-year PFS } \\
40 \%\end{array}$ & $(60)$ \\
\hline $\begin{array}{l}\text { Illerhaus, } \\
2009\end{array}$ & $\begin{array}{l}\text { HD-MTX + procarbazine + } \\
\text { CCNU }\end{array}$ & II & 29 & 70 & 15.4 & 5.9 & $(61)$ \\
\hline Roth, 2012 & HD-MTX-based chemotherapy & III & 126 & $\geq 70$ & 12.5 & 4 & $(62)$ \\
\hline Olivier, 2014 & $\begin{array}{l}\text { HD-MTX + VDS + PRED + } \\
\text { idarubicin }\end{array}$ & $\mathrm{I}$ & 35 & 65 & 19 & 13 & $(63)$ \\
\hline Omuro, 2015 & $\begin{array}{l}\text { HD-MTX + TMZ vs. } \\
\text { HD-MTX + PCZ + VCR } \rightarrow \\
\text { cytarabine (MPV-A) }\end{array}$ & II & $\begin{array}{l}48 \\
47\end{array}$ & $\begin{array}{l}73 \\
72\end{array}$ & $\begin{array}{l}14 \\
31\end{array}$ & $\begin{array}{l}6.1 \\
9.5\end{array}$ & (64) \\
\hline $\begin{array}{l}\text { Pulczynski, } \\
2015\end{array}$ & $\begin{array}{l}\text { HD-MTX + IT liposomal } \\
\text { cytarabine } \rightarrow \text { TMZ maintenance }\end{array}$ & II & 27 & 70 & $\begin{array}{l}\text { 2-year OS } \\
55.6 \%\end{array}$ & $\begin{array}{c}\text { 2-year PFS } \\
44.4 \%\end{array}$ & $(65)$ \\
\hline
\end{tabular}

OS, overall survival; PFS, progression-free survival; HD-MTX, high-dose methotrexate; TMZ, temozolomide; R, rituximab; IT, intrathecal injection therapy; VDS, vindesine; PRED, prednisone; PCZ, procarbazine; VCR, vincristine.

Table III. Memorial Sloan-Kettering Cancer Center prognostic model.

\begin{tabular}{llc}
\hline $\begin{array}{l}\text { Parameters } \\
\text { Age, KPS) }\end{array}$ & $\begin{array}{c}\text { Prognostic } \\
\text { groups }\end{array}$ & $\begin{array}{c}\text { Median OS, } \\
\text { years }\end{array}$ \\
\hline Age $\leq 50$ years & Age $\leq 50$ years & 8.5 \\
or $>50$ years; & Age $>50$ years & 3.2 \\
KPS $<70$ & and KPS $\geq 70$ & \\
or $\geq 70$ & Age $>50$ years & 1.1 \\
& and KPS $<70$ & \\
\hline
\end{tabular}

KPS, Karnofsky performance status; OS, overall survival. Data taken from study by Abrey et al (70).

transplantation (HDT/ASCT) and the use of thiotepa in a HDT regimen have also been identified as independent prognostic predictors for OS and PFS, respectively. Multivariate analysis identified non-CR at HDT/ASCT as an independent prognostic factor for poor OS (75). Notably, patients treated with thiotepa-containing HDT had a significantly superior 5-year PFS and OS compared with those receiving HDT without thiotepa (75). Bcl-6 expression has also been determined to be a favorable prognostic marker (76). Bcl-6 expression and high KPS, as independent prognostic parameters, have been associated with a favorable outcome (77). In addition, an Eastern Cooperative Oncology Group (ECOG) score of $\leq 2$, multiple brain lesions, a maximum tumor diameter of $<5 \mathrm{~cm}$ and
Table IV. International extranodal lymphoma study group score.

\begin{tabular}{lcc}
\hline $\begin{array}{l}\text { Parameters } \\
\text { (each factor, 1 point) }\end{array}$ & $\begin{array}{c}\text { Prognostic groups } \\
\text { (according to the score) }\end{array}$ & $\begin{array}{c}\text { 2-Year } \\
\text { OS, \% }\end{array}$ \\
\hline Age >60 years; ECOG & $0-1$ & 80 \\
PS >1; LDH >normal & $2-3$ & 48 \\
level; high CSF protein; & $4-5$ & 15 \\
deep brain lesions & & \\
\hline
\end{tabular}

CSF, cerebrospinal fluid; ECOG, Eastern Cooperative Oncology Group; PS, performance status; LDH, lactate dehydrogenase; OS, overall survival. Data taken from study by Ferreri et al (71).

$\mathrm{CD} 0^{+}$expression were found to be significantly associated with a prolonged OS (78). Furthermore, the texture analysis of contrast-enhanced MRI may have the potential to predict PCNSL prognosis. In a previous study, grey-level co-occurrence matrix-homogeneity $(<0.2864)$ was associated with a favorable survival and could be considered an independent predictor (79). Alame et al (80) reported that the expression of programmed death-1 protein (PD-1) on tumor-infiltrating lymphocytes (TILs) and programmed death-1 ligand (PD-L1) on tumor-associated macrophages was correlated with favorable survival. The serum level of soluble PD-L1 (sPD-L1) has also been reported to act as a reliable biomarker to predict the probability of relapse and survival outcome in patients with PCNSL; sPD-L1 $(<0.432 \mathrm{ng} / \mathrm{ml})$ has been associated with 
Table V. Prognostic markers associated with PCNSL.

A, Favorable prognostic markers in HIV-associated PCNSL

\begin{tabular}{ll}
\hline First author, year & \multicolumn{1}{c}{ Prognostic markers } \\
\hline Gopal, 2012 & CD4 count $>200$ cells $/ \mu 1$ \\
& HIV RNA viral load $<400$ copies $/ \mathrm{ml}$ \\
\hline
\end{tabular}

B, Favorable prognostic markers

First author, year

Prognostic markers

(Refs.)

Weller, 2012

Makino, 2015

Gross total resection after operation

Nakasu, 2016

Completion of three cycles of HD-MTX chemotherapy

Kondo, 2019

CR status after completion of initial HD-MTX

Levy, 2008

CR status at HDT/ASCT, thiotepa use in HDT regimen

Bcl-6

Preusser, 2010

Bcl-6 expression and high KPS

Niparuck, 2019

ECOG score $\leq 2$, multiple brain lesions, MTD $<5 \mathrm{~cm}, \mathrm{CD} 10^{+}$

Chen, 2019

GLCM-homogeneity $(<0.2864)$

PD- 1 on TILs and PD-L1 on TAMs

Alame, 2020

Serum level of soluble PD-L1 $(<0.432 \mathrm{ng} / \mathrm{ml})$

Cambruzzi, 2020

Expression of MHC II genes, expression of bcl-6, IMO2 and CD10

Nayyar, 2019

CD79b mutations

Kim, 2019

tPD-L1' patients with a large number of $\mathrm{CD}^{+}$or PD- $1^{+}$TILs

\section{C, Poor prognostic markers}

First author, year

Prognostic markers

(Refs.)

Villano, 2011

Patients aged 0-49 years: Male sex, HIV infection and African-American

Yuan, 2020

descent; patient aged $>50$ years: Increasing age

Tabouret, 2017

ECOG $>3$ and multifocal lesions

Infratentorial location and large tumor volume $\left(>11.4 \mathrm{~cm}^{3}\right)$

Chunsong, 2006

CXCL13

Le, 2019

Anemia

Oyama, 2007

EBV-positive

Wu, 2019

ABCB1 rs1045642 CC genotype, PS >2 and older age

Yang, 2020

Elevated CSF IL-10 and STAT3 phosphorylation

Hatzl, 2020

DEL

Yin, 2019

Bcl-2 gene aberrations and DH

Villa, 2019

Bcl-6 rearrangements

Cambruzzi, 2020

Expression of MUM1, cyclin D2, p53, CD5, FOXP1, ICAM1, HLA-DR and bcl-2; and strong FOXP1 positivity, myc and bcl-2 overexpression, bcl-6 translocations, and high Ki-67 index

Takano, 2018

Mondello, 2020

MyD88 mutations

Tumor expression of activated STAT6, and elevated levels of IL-4 and IL-10

Serum $\beta 2-\mathrm{MG}(\geq 1.8 \mathrm{~g} / \mathrm{ml})$

Kim, 2019 tPD-L1 $1^{+}$patients with a small number of $\mathrm{CD}^{+}$or PD- $1^{+} \mathrm{TILs}$

PCNSL, primary central nervous system lymphoma; HD-MTX, high-dose methotrexate; CR, complete remission; HDT/ASCT, high-dose chemotherapy with autologous stem cell transplantation; ECOG, Eastern Cooperative Oncology Group; CXCL, CXC chemokine ligand; EBV, Epstein-Barr virus; MTD, maximum tumor diameter; GLCM, grey-level co-occurrence matrix; PD-1, programmed death-1; TILs, tumor-infiltrating lymphocytes; PD-L1, programmed death-1 ligand; TAMs, tumor-associated macrophages; tPD-L1, tumoral PD-L1; STAT, signal transducer and activator of transcription; PS, performance status; DEL, double-expression lymphoma; DH, bcl-2/c-myc gene double-hit; $\beta 2-\mathrm{MG}, \beta 2$-microglobulin. 
a longer OS and PFS (81). The expression of MHC II genes was also found to predict a favorable outcome following chemotherapy (82). The expression of bcl-6, IMO2 and CD10 has also been associated with a favorable prognosis (82).

Male sex, HIV infection and being of African-American descent have been reported as independent predictors of mortality in patients aged 0-49 years. In patients aged $>50$ years, only advanced age was associated with decreased survival (7). Furthermore, ECOG $>3$ and multifocal lesions have been found to be significant independent unfavorable prognostic markers for PFS (83). Infratentorial location and large tumor volume $\left(>11.4 \mathrm{~cm}^{3}\right)$ were also revealed to be associated with poor OS and PFS, respectively (84). CXCL13 and the presence of anemia have also been found to be poor prognostic markers in PCNSL $(85,86)$. In addition, patients with EBV-positive PCNSL had a shorter OS than those with EBV-negative PCNSL (87). In a previous study, the most important prognostic factors associated with a higher risk of progression were ABCB1 rs1045642 CC genotype, ECOG performance status $>2$ and older age (88). Elevated CSF IL-10 and STAT3 phosphorylation have also been shown to be associated with a worse prognosis (89). Furthermore, as demonstrated by immunohistochemistry, concurrent expression of myc and bcl-2, also known as double-expression lymphoma, was associated with inferior OS and PFS (90). Bcl-2 gene aberrations, bcl-2/c-myc gene double-hit and bcl-6 rearrangements have also been associated with adverse outcomes $(91,92)$. In addition, the expression levels of MUM1, cyclin D2, p53, CD5, FOXP1, ICAM1, HLA-DR and bcl-2 have been related to poor prognosis. A strong FOXP1 positivity, myc and bcl-2 overexpression, bcl- 6 translocations, and a high Ki-67 index have been associated with unfavorable prognosis in a previous study (82). Takano et al (93) reported that MyD88 mutations occurred more frequently in elderly patients and were associated with poor prognosis. However, another previous study demonstrated that MyD88 mutations were not associated with a change in PFS or OS, whereas CD79b mutations were associated with improved PFS and OS (94). The tumor expression levels of activated STAT6, and elevated levels of CSF IL-4 and IL-10 have been suggested as potential adverse prognostic biomarkers for PCNSL (95). Serum $\beta 2-M G(\geq 1.8 \mathrm{~g} / \mathrm{ml})$ may be associated with a shorter OS in PCNSL (96). It has also been reported that tumoral PD-L1 (tPD-L1) expression and the number of PD-1 $1^{+}$TILs were independent prognostic factors for PCNS-DLBCL. tPD-L1 $1^{+}$patients with a small number of $\mathrm{CD} 8^{+}$or PD- $1^{+}$TILs exhibited the worst prognosis, whereas $\mathrm{tPD}-\mathrm{L1}^{-}$patients with a large number of $\mathrm{CD}^{+}$or PD-1+ ${ }^{+}$TILs exhibited the best prognosis (97). Notably, in HIV-related PCNSL, the CD4 count and HIV RNA viral load have been found to be correlated with survival (98).

\section{Treatment}

PCNSL often has a favorable response to chemotherapy and radiotherapy (RT). Currently, the mainstay of treatment for patients with PCNSL is induction chemotherapy, which aims for $\mathrm{CR}$, followed by consolidation therapy that aims to eradicate residual disease and improve OS (99). The treatment of PCNSL is based on age and performance status (100).
Older age is associated with an accumulation of physiological deficits that alter the pharmacokinetics and pharmacodynamics of therapies, and may increase the risk of toxicity. Performance status should be considered an important predictor of OS and drug toxicity. When selecting a treatment for elderly patients, multiple parameters should be considered. The American Society of Clinical Oncology Guidelines advocates for the use of geriatric assessment tools in patients $\geq 65$ years who have received chemotherapy to identify vulnerabilities not routinely captured in oncology assessments (101). These tools are useful in predicting chemotherapeutic toxicity and mortality. The chemotherapy risk assessment scale for high-age patients (CRASH) score developed by Extermann et al (102) considers the specific chemotherapy regimen to be used, laboratory values, and functional, mental and nutritional status assessments. The CRASH score then stratifies patients into four risk categories: Low, medium-low, medium-high and high. The routine use of such a score may increase the proportion of elderly patients that receive optimal treatment. For example, a 'fit elderly' individual may tolerate standard doses and schedules of chemotherapeutic drugs, and may thus reap the same benefits as younger patients.

In the elderly population, an individualized treatment that aims at prolonging survival while minimizing toxicity is required (Fig. 3). Despite the fact that the median OS of all patients has doubled over the last 40 years, this survival benefit is restricted to patients aged $<70$ years (66). Therefore, identifying effective and tolerable treatment strategies for elderly patients is one of the key future challenges.

Steroid treatment. PCNSL is sensitive to corticosteroids, with reported response rates between 20 and 40\% $(103,104)$. Corticosteroids have been shown to decrease tumor-associated edema and may result in a partial radiographic regression of tumors. However, certain studies have reported that the preoperative use of steroids can compromise the efficacy of brain biopsy in patients with PCNSL $(105,106)$. As such, the classic rationale recommends withholding steroid treatment for $\geq 14$ days prior to a brain biopsy (24). An initial response to corticosteroids has been reported to be associated with a favorable outcome in PCNSL (107). As such, corticosteroids should be avoided prior to biopsy as much as possible, in order to decrease their impact on diagnosis. However, when the symptoms are serious and life-threatening, corticosteroids should be used to relieve the symptoms and prevent cerebral herniation. Treatment should be given in the smallest possible dose and for the shortest possible time to avoid long-term adverse reactions. In addition, almost all patients relapse quickly after an initial response to corticosteroids (108).

\section{Induction therapy}

$H D-M T X$. In newly diagnosed patients with PCNSL, the standard management approach, according to the 2018 NCCN guidelines (109), is HD-MTX-based chemotherapy, followed by consolidation therapy with whole brain RT (WBRT). MTX is an antifolate that suppresses DNA synthesis by inhibiting dihydrofolate reductase activity in purine and thymidine synthesis, which controls the expression of glucocorticoid receptors in blood cells $(110,111)$. HD-MTX, one of the few drugs able to penetrate the blood-brain barrier (BBB), is 


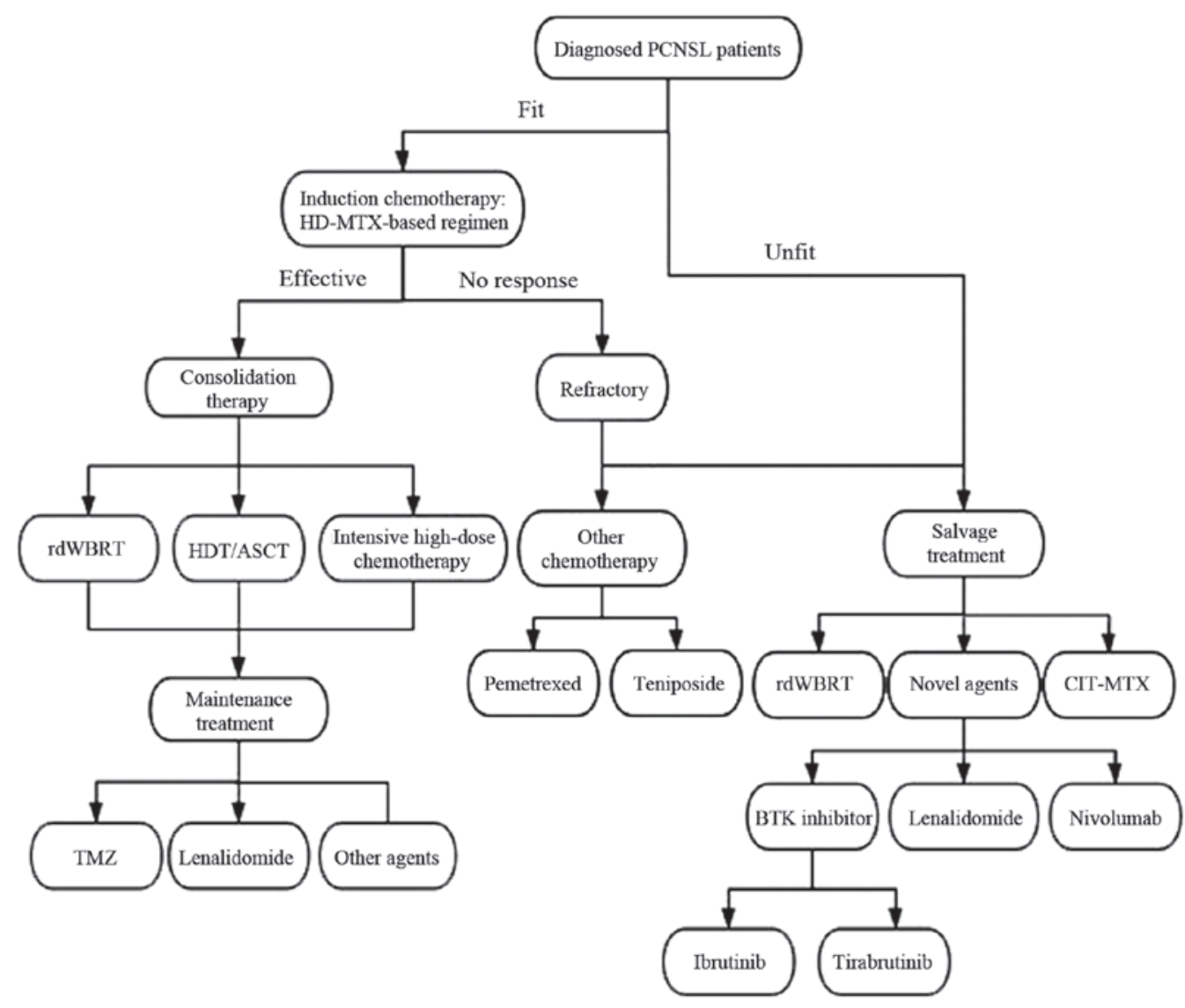

Figure 3. Key points in the treatment of PCNSL in elderly patients. PCNSL, primary central nervous system lymphoma; HD-MTX, high-dose methotrexate; rdWBRT, reduced-dose whole brain radiotherapy; HDT/ASCT, high-dose chemotherapy with autologous stem cell transplantation; TMZ, temozolomide; CIT, continuous intrathecal injection therapy; BTK, Bruton's tyrosine kinase.

commonly used as a first-line treatment for PCNSL. When combined with other agents, such as HD-cytarabine, temozolomide (TMZ) and rituximab, HD-MTX combination therapy has been revealed to offer a better prognosis compared with that of single therapeutics alone $(55,112,113)$. Moreover, HD-MTX is considered a relatively safe treatment for patients with PCNSL regardless of age (114), and is even tolerable to patients aged $\geq 80$ years (115). While HD-MTX-based treatment is widely accepted in clinical settings, $50 \%$ of patients may have a risk of progression or recurrence, and HD-MTX can cause renal dysfunction $(116,117)$.

Pemetrexed. Pemetrexed is also an antifolate and is similar to MTX in its ability to penetrate the CNS; however, it has an advantage of targeting more than one site in folate metabolism. Pemetrexed interrupts purine synthesis by inhibiting thymidylate synthase and dihydrofolate reductase, and interrupts pyrimidine synthesis via inhibition of glycinamide ribonucleotide formyltransferase and aminoimidazole carboxamide for methyltransferase (118). Raizer et al (119) investigated the antitumor activity and safety of pemetrexed in recurrent PCNSL, and found that pemetrexed had single-agent activity in R/R PCNSL and possible toxicities were due to the use of higher than standard doses. Han et al (120) studied 12 patients with newly diagnosed PCNSL that were $>65$ years old; four patients presented $\mathrm{CR}$ and six patients had partial response (PR), with a median PFS of 9.0 months and a median OS of
19.5 months. This previous study demonstrated that the single agent pemetrexed may be feasible, active and well tolerated in elderly patients with PCNSL.

Rituximab. Rituximab is a large, monoclonal antibody against CD20. Since $\sim 98 \%$ of small molecule drugs and most macromolecular drugs are unable to pass through the BBB (121), the addition of rituximab to HDMTX-based regimens remains controversial.

Several clinical studies have demonstrated that rituximab can promote CR and prolong survival (113,122-125), an effect that occurs regardless of age (126). Houillier et al (58) reached the same conclusion, and revealed that the addition of rituximab improved the response rate of an MTX-based regimen (77 vs. 53\% without rituximab) with a good tolerance profile, except for an increased rate of leucopenia. In addition, there is evidence that disruption of the BBB by the presence of CNS lymphoma permits an enhanced penetration of rituximab into the CNS compartment to reach therapeutic concentrations (127). The international randomized trial IELSG32 suggested that the addition of rituximab to HD-MTX and HD-cytarabine improved response, PFS and OS (128). A meta-analysis suggested a possible beneficial effect of rituximab on PFS and supported the addition of rituximab when MTX-based chemotherapy was planned (129).

Conversely, in the recently published HOVON trial, rituximab was not found to have an effect on response or survival in 
A

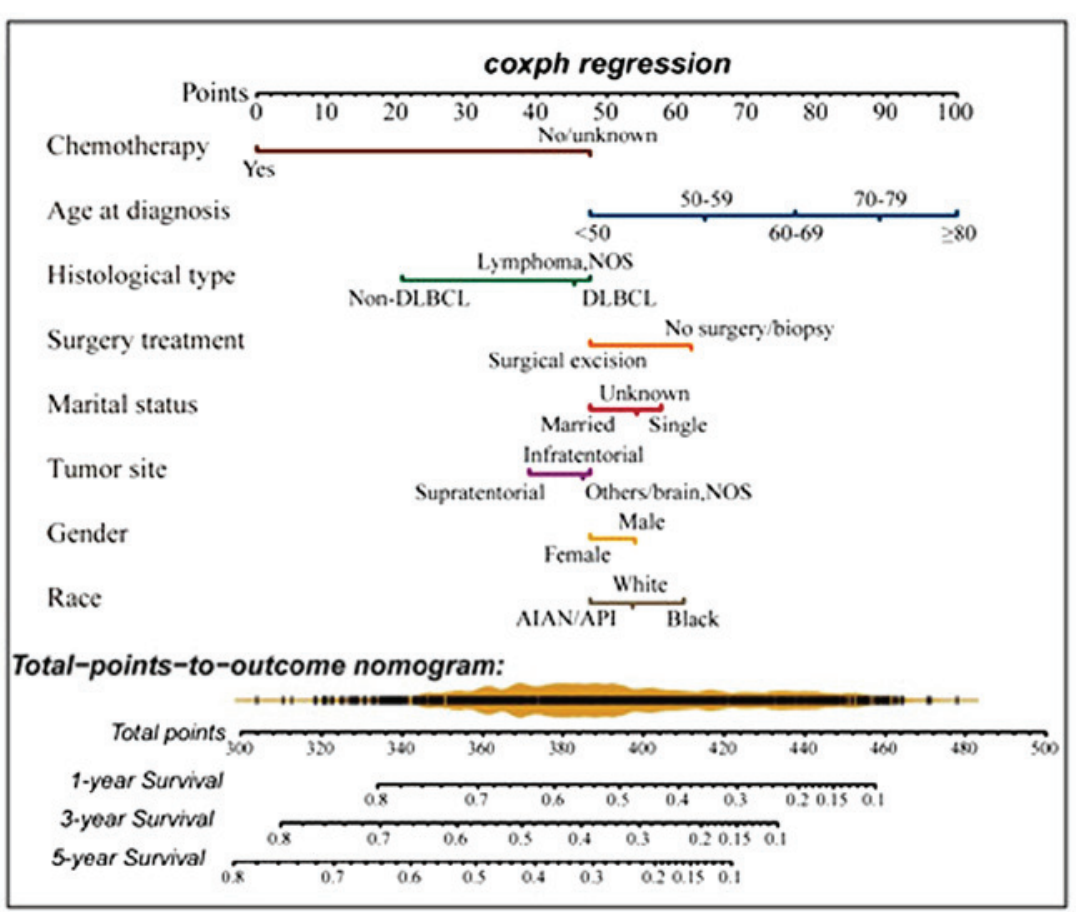

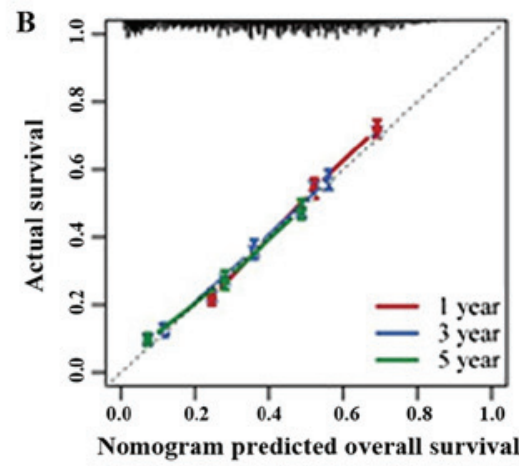

C

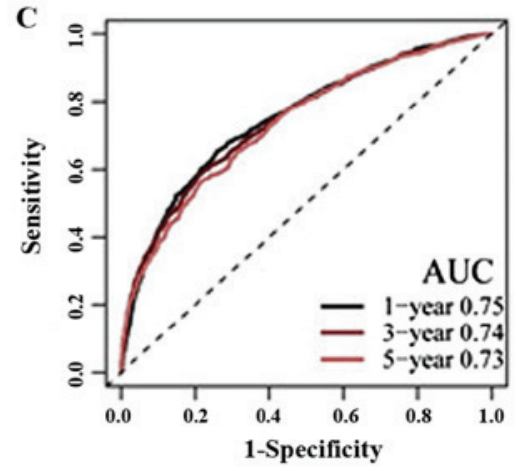

Figure 4. Nomogram development and internal validation. (A) Nomogram construction to estimate the probability of 1-, 3- and 5-years OS for PCNSL. (B) Calibration plot of the nomogram for predicting the probability of OS at 1,3 and 5 years. (C) Time-dependent ROC curve analysis confirmed that the nomogram had the best performance. Images taken from the study by Deng et al (136). AUC, area under the curve; OS, overall survival; PCNSL, primary central nervous system lymphoma; ROC, receiver operating characteristic.

the treatment of PCNSL. There was no difference in survival or response for patients treated with or without rituximab, after a median follow up of 32.9 months (130).

Teniposide. Teniposide is a topoisomerase inhibitor, highly lipopolysaccharide, which can cross the BBB and has been used in the treatment of PCNSL $(131,132)$. The penetration of teniposide has been widely examined in normal brain tissue and in brain tumor tissue (133). The phase II trial by the European Organization for Research and Treatment of Cancer Lymphoma Group indicated that the use of MTX, teniposide, carmostine and methylprednisolone resulted in improved outcomes, with a 3-year OS rate of 58\% (132). A randomized phase II trial also identified that a chemotherapy regimen, which included fotemustine, teniposide and dexamethasone, was an effective and safe protocol for treating patients with newly diagnosed PCNSL (134). In a previous retrospective study, 56 patients were admitted, with a median age of 54.5 years. The results indicated that the HD-MTX + teniposide regimen, compared with HD-MTX alone, not only improved the CR rate in the short-term, but also improved long-term efficacy in the treatment of PCNSL (135).

Combined surgery, and chemotherapy or RT. A previous study demonstrated that the combination of surgical excision and chemotherapy conferred a more favorable outcome than chemotherapy alone, suggesting that multimodal treatment might be more beneficial. With regard to the specific extent of excision, a more extensive resection was revealed to be associated with a more favorable survival (136). Kinslow et al (137) identified a significant survival advantage for patients with PCNSL treated with adjuvant RT following surgery.

A new nomogram model (Fig. 4) was established, which may offer an individualized quantitative potential benefit from surgical excision to patients with PCNSL (136). The nomogram model was internally validated using the bootstrap validation method. The nomogram predicted 1-, 3- and 5-year OS rate for patients with PCNSL based on the results of a multivariate Cox analysis (Fig. 4A). Calibration curves showed the consistency between the nomogram-predicted survival and the actual results (Fig. 4B). In addition, the nomogram model had favorable prognostic accuracy for OS through the analysis of the receiver operating characteristic (Fig. 4C). This practical clinical tool may provide more distinct and direct data to assist clinical decision-making and optimization of therapeutic approaches in clinical care (136).

Consolidation therapy. It has been reported that a total of 20-30\% of patients with PCNSL relapse within 6 months, even after intensive MTX treatment (113), indicating consolidation therapy is necessary to eliminate minimal residual disease in PCNSL. Until the beginning of this century, WBRT was the only consolidation therapy available for PCNSL. Thereafter, clinical trials investigating various types of consolidation have fit into an emerging concept, which suggests that the treatment of PCNSL is most efficient if HD-MTX-based treatment is followed by a type of consolidation treatment (138).

WBRT. WBRT is an important means of treating PCNSL with a total response rate of $90 \%$; however, the OS has been reported to be only 12-16 months and it can be accompanied 
by marked neurotoxicity (139). Radiation-induced neurotoxicity includes progressive severe cognitive dysfunction, ataxia and urinary incontinence. The elderly are also susceptible to the detrimental cognitive side effects of WBRT. In a previous study, neurotoxicity occurred in $19-83 \%$ of patients aged $>60$ years who received WBRT following MTX-based chemotherapy (2). Furthermore, neurotoxicity tends to occur more severely and rapidly in patients with advanced age at the time of treatment (2).

As WBRT is associated with a substantial risk for cognitive impairment, alternative consolidation methods have been used, including reduced-dose WBRT (rdWBRT). A study that used rdWBRT as consolidation therapy reported good PFS and OS rates following treatment (140). Furthermore, a recent study demonstrated that rdWBRT ( $\leq 23.4$ Gy) combined with HD-MTX exhibited no statistical difference in terms of OS and PFS, as compared with higher-dose WBRT, and suggested that patients aged $<60$ years might benefit from rdWBRT (141). The value of consolidation WBRT and the optimal dose of RT remain controversial, particularly in older patients.

HDT/ASCT. Based on the available data, HDT/ASCT as consolidation therapy for patients with PCNSL is considered an effective and feasible strategy, with less overall neurotoxicity compared with WBRT; however, a higher risk of treatment-related mortality has been reported with HDT/ASCT compared with WBRT (142). Conditioning regimens that contain CNS-penetrant agents, including carmustine, thiotepa and busulfan, have exhibited the most encouraging results. In a retrospective study, patients treated with thiotepa-containing HDT/ASCT were found to have a significantly better 2-year PFS (62\%) and OS (70.8\%); however, the associated toxicity limited their use in elderly patients. Therefore, for selected 'biologically young' patients, MTX-based chemotherapy with HDT/ASCT as consolidation therapy is a viable option (143).

Intensive HD chemotherapy. Intensive HD chemotherapy as consolidation therapy may also be a reasonable option for those patients who respond to first-line chemotherapy, but the advanced age and poor general condition of most patients are major obstacles to this approach. While intensive consolidation may improve outcomes in patients aged $<70$ years, HD chemotherapy is not an option for the majority of elderly patients with PCNSL (144). A previous study showed no additional benefit of a prolonged consolidation treatment with cytarabine following HD-MTX-based chemotherapy in the elderly (58).

Maintenance treatment. In elderly patients who cannot tolerate consolidation therapy, maintenance treatment may serve as a feasible alternative approach to prolonging remission, delaying relapses and maintaining tumor dormancy. Several available and promising chemotherapy and targeted agents, such as TMZ, procarbazine, lenalidomide and ibrutinib may serve a role in maintenance therapy for PCNSL (145). To the best of our knowledge, there has been no randomized clinical trial conducted proving that maintenance treatment is beneficial in PCNSL.

TMZ, an oral alkylating agent, is known to effectively penetrate the $\mathrm{BBB}$ and have a tolerable toxicity profile. It is generally an easily administered drug, given orally for 5 days for a 4-week cycle. TMZ has been incorporated into induction treatment for elderly patients with PCNSL $(10,64)$. It has been reported that TMZ may be effective as single-agent maintenance therapy against PCNSL in elderly patients to maintain quality of life and functional independence with the best neurocognitive preservation results (65). Notably, a previous study introduced TMZ as a maintenance treatment in elderly patients with promising results (65). It is a potential option for elderly patients with PCNSL, who have achieved CR or PR and wish to avoid WBRT neurotoxicity, particularly those considered unsuitable for ASCT (117).

Salvage treatment of relapsed/refractory $(R / R)$ PCNSL. Despite advances in induction and consolidation regimens, $10-35 \%$ of patients with PCNSL have been reported to become refractory to initial treatment and $35-60 \%$ relapse within 1-2 years $(9,146)$. The ideal approach to treat patients with $R / R$ PCNSL is unclear.

Continuous intrathecal injection therapy of MTX (CIT-MTX). CIT-MTX has been reported to be a promising therapy not only for patients treated with conventional common therapy, but also those at high risk from HD-MTX. A better prognosis in patients treated with CIT-MTX may be derived from the stable concentration of MTX in the CSF (147).

rdWBRT and HDT/ASCT. HDT/ASCT has been used to treat patients with R/R PCNSL with a 3-year event-free survival of $53 \%$ and an OS of $64 \%$ (148). In relapsed patients, HDT/ASCT appears to have an equivalent or improved efficacy compared with other salvage therapies; however, the risk of treatment-related mortality is a consideration (85). A previous study suggested that HDT/ASCT and rdWBRT may be associated with white matter abnormalities in patients with PCNSL who have achieved long-term remission, and that patients treated with rdWBRT may be at greater risk (149). Moreover, HDT/ASCT cannot be used to treat frail elderly patients.

Allogeneic hematopoietic cell transplantation (Allo-HCT). Allo-HCT has been studied in R/R PCNSL; however, to the best of our knowledge, the only available data is from two case reports by Atilla et al (150) and Varadi et al (151). The results of these studies were encouraging, suggesting Allo-HCT might be an alternative option for R/R PCNSL. Evaluating the safety and efficacy of allo-HCT in PCNSL requires further clinical trials, particularly phase III randomized trials.

Chimeric antigen receptor T-cell (CART-cell) therapy. Cumulative data have revealed that immunotherapy with CART-cells provides hope for a high response rate in patients with R/R DLBCL (152). However, clinical trials on CART-cell therapy usually rule out PCNSL because of the occurrence of lethal cerebral edema after CART-cell therapy. A case report from Tu et al (152) reported that combination treatment with CD19- and CD70-specific CART-cells may effectively target PCNSL and maintain disease-free survival without inducing cytokine release syndrome or CART-related encephalopathy syndrome, thus indicating that CART-cell therapy may be a potentially promising treatment for patients with $\mathrm{R} / \mathrm{R}$ PCNS-DLBCL. 
Novel agents. Based on new insights into the pathogenesis of PCNSL, novel agents have been introduced to treat PCNSL. These agents, such as ibrutinib (153), tirabrutinib (154), lenalidomide (137), pomalidomide (155) and nivolumab (156), are currently being evaluated both as single agents and in combination with other agents in clinical trials. The incorporation of novel agents into the treatment of PCNSL may enable the application of precision medicine in the treatment of patients with R/R PCNSL.

Bruton's tyrosine kinase (BTK) inhibitor. BTK, a nonreceptor protein kinase, is important for the amplification of B-cell signaling. BTK integrates BCR and Toll-like receptor signaling, linking them to downstream NF- $\mathrm{B}$ signaling; therefore, it may be considered an attractive candidate for targeted inhibition $(4,157)$. Mutations leading to activation of the NF- $\mathrm{B}$ signaling pathway, such as mutations in MyD88, CARD11 and CD79, and TNFAIP3 and TBL1XR1 deletions, have been observed in almost all PCNSL cases, thus indicating that $N F-\kappa B$ activation may serve a role in the pathogenesis of PCNS-DLBCL and could represent a potential therapeutic target $(4,157)$.

Ibrutinib, a small molecule BTK inhibitor, has been identified as a potential novel therapeutic agent for the treatment of PCNSL. A small retrospective study in R/R PCNSL demonstrated the feasibility of ibrutinib treatment, with promising responses reported in several patients (158). Even patients without genomic alterations in the BCR pathway have been shown to respond to ibrutinib (159); however, as a single drug, ibrutinib is prone to drug resistance, limiting PFS. A phase II study on ibrutinib revealed treatment resistance in the absence of a CARD11 mutation and presence of a mutation in the BCR pathway (160). A phase Ib trial investigating ibrutinib monotherapy for 2 weeks, followed by its combination with conventional chemotherapies, including adjusted TMZ, etoposide, doxorubicin, dexamethasone, cytarabine and rituximab, demonstrated a PR rate of $83 \%$ prior to the initiation of the combination regimen, with a subsequent $\mathrm{CR}$ rate of $86 \%$ following combination chemotherapy in the patients with $R / R$ PCNSL (153). Resistance to ibrutinib monotherapy could be overcome through combination regimens with chemotherapy and/or targeted biological agents.

Tirabrutinib is a second-generation, potent, highly selective, irreversible oral BTK inhibitor. A phase I/II study evaluated the safety, tolerability, efficacy and pharmacokinetics of tirabrutinib in Japanese patients with R/R PCNSL, and displayed an objective response rate (ORR) of $64 \%$ and PFS of 2.9 months. Furthermore, median OS was not reached, indicating a favorable efficacy of tirabrutinib in patients with R/R PCNSL (154).

Immunomodulatory drugs (IMIDs). IMIDs, such as lenalidomide and pomalidomide, are thalidomide-derived agents with antiproliferative and immunomodulatory properties. These drugs have been tested in recurrent PCNSL. A previous study indicated that lenalidomide may exert cytotoxic effects relevant to PCNSL, including the inhibition of IRF4 and myc pro-survival signals (161). Lenalidomide has been used as a single agent in the treatment of patients with relapsing PCNSL, with two patients achieving CR in a small retrospective cohort (162). The activity was confirmed in a phase I trial, with $9 / 14$ patients with R/R PCNSL treated with lenalidomide monotherapy exhibiting objective response (163). A phase II study evaluated lenalidomide in combination with rituximab in 50 patients with R/R PCNSL or primary vitreoretinal lymphoma, and found an ORR of $35 \%$ (164). Maintenance therapy with lenalidomide alone was recommended to responding patients, and the median PFS and OS were 7.8 and 17.7 months, respectively (164). In addition, a previous study revealed that reduced-dose MTX-based treatment followed by low-dose lenalidomide maintenance was well-tolerated in patients aged $\geq 70$ years, and associated with excellent PFS and OS (136). Pomalidomide is a novel immunomodulatory drug with anti-lymphoma activity. The combination of pomalidomide with dexamethasone resulted in an ORR of $48 \%$ and a median PFS of 5.3 months (155).

PI3K/AKT/mTOR signaling inhibitors. Mutations and copy number variations of PIK3CA and PTEN have been detected in next-generation sequencing analyses of PCNSL $(165,166)$. These genes are associated with the $\mathrm{PI} 3 \mathrm{~K} / \mathrm{AKT} / \mathrm{mTOR}$ signaling pathway, indicating the potential role of this pathway in the pathogenesis of PCNSL (167). $\mathrm{PI} 3 \mathrm{~K} / \mathrm{AKT} / \mathrm{mTOR}$ inhibitors have also been used to treat $\mathrm{R} / \mathrm{R}$ PCNSL. In a formal phase II trial, the first targeted agent investigated, the mTOR inhibitor temsirolimus, was used to treat 37 patients with R/R PCNSL, with an acceptable ORR of $54 \%$, a median OS of 3.7 months, and a poor median PFS of 2.1 months (168). Moreover, in a small retrospective series, the response rate to the PI3K inhibitor buparlisib was even lower (1/4 of patients responded) (169). These findings indicate that PI3K/AKT/mTOR inhibitors may not be appropriate as a single agent for R/R PCNSL treatment.

Notably, it is common for the active PI3K/AKT/mTOR pathway in PCNSL to carry a CD79B mutation (159). In addition, in an ABC-DLBCL model, ibrutinib was reported to achieve a synergistic effect when combined with $\mathrm{PI} 3 \mathrm{~K} / \mathrm{AKT} / \mathrm{mTOR}$ inhibitors through concerted inhibition of multiple pathways $(170,171)$.

Immune checkpoint inhibitors. PD-1 is an inhibitory receptor expressed on activated T cells, and its interaction with PD-L1 produces an immunosuppressive activity, protecting tumor cells from antitumor immunity and possibly releasing sPD-L1 from PD-L1-expressing tumor cells. Since immune checkpoint inhibitors that block PD-1 have been reported to be effective in patients with $\mathrm{R} / \mathrm{R}$ lymphoma, the role of $\mathrm{PD}-1$ inhibitors as a salvage treatment has been emerging in patients with R/R PCNSL. sPD-L1 in the serum may serve as a feasible biomarker for determining a risk-adapted treatment strategy for patients with PCNSL (91).

Nivolumab, an antibody targeting PD-1, and dendritic cell vaccinations have been reported to lead to CR in one case (172). In addition, in a small case series, a response was recorded in four patients with PCNSL treated with nivolumab (156). Low-dose nivolumab has been reported to induce durable CR in relapsed PCNS-DLBCL (173). In summary, PD-1 blockade with nivolumab could be considered an option in the treatment of R/R PCNSL. 
Cyclin-dependent kinase (CDK)4/6 inhibitors. The biallelic deletion of CDKN2A has been observed in 44\% of PCNSL cases, suggesting that CDKN2A loss may be an early clonal event in PCNSL evolution, raising the possibility of investigating the efficacy of CDK4/6 inhibitors in patients with PCNSL (94).

\section{Conclusion}

The incidence of PCNSL in immunocompetent elderly patients, particularly men, is increasing. Notably, the symptoms of PCNSL and brain imaging are often non-specific. For the diagnosis of CNSL, imaging-guided stereotactic biopsy is regarded as the gold standard; if stereotactic biopsy is not possible or conclusive, certain biomarkers can help establish a diagnosis. PCNSL has a very poor prognosis in the elderly, even though several prognostic scoring systems have been generated and numerous prognostic markers for PCNSL have been reported. Therefore, the treatment of elderly patients with PCNSL remains challenging. An individualized treatment that aims at prolonging survival while minimizing toxicity is required. It is unlikely that a novel agent could have curative effects as a monotherapy; however, its rational combination with chemotherapeutic agents or its combination with other new drugs may have therapeutic potential. Consequently, patients should be urged to enter clinical trials, whenever possible. Further clinical studies should offer more evidence of optimal doses or combinations of polychemotherapeutic regimens and new drugs in the elderly.

\section{Acknowledgements}

Not applicable.

\section{Funding}

No funding was received.

\section{Availability of data and materials}

Not applicable.

\section{Authors' contributions}

YL is responsible for writing the review. QY revised the review. FZ contributed to finalize the draft. QY and FZ confirm the authenticity of all the raw data. All authors read and approved the final manuscript.

\section{Ethics approval and consent to participate}

Not applicable.

\section{Patient consent for publication}

Not applicable.

\section{Competing interests}

The authors declare that they have no competing interests.

\section{References}

1. Bailey P: Intracranial sarcomatous tumors of leptomeingeal origin. Arch Surg 18: 1359-1402, 1929.

2. Siegal T and Bairey O: Primary CNS lymphoma in the elderly: The challenge. Acta Haematol 141: 138-145, 2019.

3. Mulazzani M, Huber M, Borchard S, Langer S, Angele B, Schuh E, Meinl E, Dreyling M, Birnbaum T, Straube A, et al: APRIL and BAFF: Novel biomarkers for central nervous system lymphoma. J Hematol Oncol 12: 102, 2019.

4. Braggio E, Van Wier S, Ojha J, McPhail E, Asmann YW, Egan J, da Silva JA, Schiff D, Lopes MB, Decker PA, et al: Genome-wide analysis uncovers novel recurrent alterations in primary central nervous system lymphomas. Clin Cancer Res 21: 3986-3994, 2015.

5. Chapuy B, Roemer MG, Stewart C, Tan Y, Abo RP, Zhang L, Dunford AJ, Meredith DM, Thorner AR, Jordanova ES, et al: Targetable genetic features of primary testicular and primary central nervous system lymphomas. Blood 27: 869-881, 2016.

6. Campo E, Swerdlow SH, Harris NL, Pileri S, Stein H and Jaffe ES: The 2008 WHO classification of lymphoid neoplasms and beyond: Evolving concepts and practical applications. Blood 117: 5019-5032, 2011.

7. Villano JL, Koshy M, Shaikh H, Dolecek TA and McCarthy BJ: Age, gender, and racial differences in incidence and survival in primary CNS lymphoma. Br J Cancer 105: 1414-1418, 2011.

8. O'Neill BP, Decker PA, Tieu C and Cerhan JR: The changing incidence of primary central nervous system lymphoma is driven primarily by the changing incidence in young and middle-aged men and differs from time trends in systemic diffuse large B-cell non-Hodgkin's lymphoma. Am J Hematol 88: 997-1000, 2013.

9. Deangelis LM and Iwamoto FM: An update on therapy of primary central nervous system lymphoma. Hematol Am Soc Hematol Educ Program 2006: 311-316, 2006.

10. Omuro AM, Taillandier L, Chinot O, Carnin C, Barrie M and Hoang-Xuan K: Temozolomide and methotrexate for primary central nervous system lymphoma in the elderly. J Neuro Oncol 85: 207-211, 2007.

11. Roth P and Hoang-Xuan K: Challenges in the treatment of elderly patients with primary central nervous system lymphoma. Curr Opin Neurol 27: 697-701, 2014.

12. Grommes C and DeAngelis LM: Primary CNS lymphoma. J Clin Oncol 35: 2410-2418, 2017.

13. Schabet M: Epidemiology of primary CNS lymphoma. J Neurooncol 43: 199-201, 1999.

14. Enblad G, Martinsson G, Baecklund E, Hesselager G, Sundström C, Amini RM and Hagberg H: Population-based experience on primary central nervous system lymphoma 2000-2012: The incidence is increasing. Acta Onco 156: 599-607, 2017.

15. Reni M, Ferreri AJ, Guha-Thakurta N, Blay JY, Dell'Oro S, Biron P and Hochberg FH: Clinical relevance of consolidation radiotherapy and other main therapeutic issues in primary central nervous system lymphomas treated with upfront high-dose methotrexate. Int J Radiat Oncol Biol Phys 51: 419-425, 2001

16. Chan SM, Hutnik CM, Heathcote JG, Orton RB and Banerjee D: Iris lymphoma in a pediatric cardiac transplant recipient: Clinicopathologic findings. Ophthalmology 107: 1479-1482, 2000.

17. Matinella A, Lanzafame M, Bonometti MA, Gajofatto A, Concia E, Vento S, Monaco S and Ferrari S: Neurological complications of HIV infection in pre-HAART and HAART era: A retrospective study. J Neurol 262: 1317-1327, 2015.

18. Engels EA, Biggar RJ, Hall HI, Cross H, Crutchfield A, Finch JL, Grigg R, Hylton T, Pawlish KS, McNeel TS and Goedert JJ: Cancer risk in people infected with human immunodeficiency virus in the United States. Int J Cancer 123: 187-194, 2008.

19. Shiels MS, Pfeiffer RM, Besson C, Clarke CA, Morton LM, Nogueira L, Pawlish K, Yanik EL, Suneja G and Engels EA: Trends in primary central nervous system lymphoma incidence and survival in the U.S. Br J Haematol 174: 417-424, 2016.

20. Bathla $G$ and Hegde A: Lymphomatous involvement of the central nervous system. Clin Radiol 71: 602-609, 2016.

21. Morell AA, Shah AH, Cavallo C, Eichberg DG, Sarkiss CA, Benveniste R, Ivan ME and Komotar RJ: Diagnosis of primary central nervous system lymphoma: A systematic review of the utility of CSF screening and the role of early brain biopsy. Neurooncol Pract 6: 415-423, 2019. 
22. Miller B, Sirotkin I and Martinez C: Review of radiologic considerations in an immunocompetent patient with primary central nervous system lymphoma. Fed Pract 36 (Suppl 5): S51-S53, 2019.

23. Lin X, Khan IRA, Seet YHC, Lee HY and Yu WY: Atypical radiological findings of primary central nervous system lymphoma. Neuroradiology 62: 669-676, 2020.

24. Scott BJ, Douglas VC, Tihan T, Rubenstein JL and Josephson SA: A systematic approach to the diagnosis of suspected central nervous system lymphoma. JAMA Neurol 70: 311-319, 2013.

25. Ferreri AJM: Therapy of primary CNS lymphoma: Role of intensity, radiation, and novel agents. Hematology Am Soc Hematol Educ Program 2017: 565-577, 2017.

26. Malikova H, Burghardtova M, Koubska E, Mandys V, Kozak T and Weichet J: Secondary central nervous system lymphoma: Spectrum of morphological MRI appearances. Neuropsychiatr Dis Treat 14: 733-740, 2018.

27. Green K and Hogg JP: Central Nervous System Lymphoma. In: StatPearls. StatPearls Publishing, Treasure Island, FL, 2020.

28. Blay JY, Ongolo-Zogo P, Sebban C, Carrie C, Thiesse P and Biron P: Primary cerebral lymphomas: Unsolved issues regarding first-line treatment, follow-up, late neurological toxicity and treatment of relapses. The FNCLCC. French Fédération Nationale des Centres de Lutte contre le Cancer. Ann Oncol 11 (Suppl 1): S39-S44, 2000.

29. Alizadeh AA, Eisen MB, Davis RE, Ma C, Lossos IS Rosenwald A, Boldrick JC, Sabet H, Tran T, Yu X, et al: Distinct types of diffuse large B-cell lymphoma identifified by gene expression profiling. Nature 403: 503-511, 2000.

30. Pasqualucci L and Dalla-Favera R: The genetic landscape of diffuse large B-cell lymphoma. Semin Hematol 52: 67-76, 2015.

31. Hans CP, Weisenburger DD, Greiner TC, Gascoyne RD, Delabie J, Ott G, Müller-Hermelink HK, Campo E, Braziel RM, Jaffe ES, et al: Confirmation of the molecular classification of diffuse large B-cell lymphoma by immunohistochemistry using a tissue microarray. Blood 103: 275-282, 2004.

32. Hoang-Xuan K, Bessell E, Bromberg J, Hottinger AF, Preusser M, Rudà R, Schlegel U, Siegal T, Soussain C, Abacioglu U, et al Diagnosis and treatment of primary CNS lymphoma in immunocompetent patients: Guidelines from the European Association for Neuro-Oncology. Lancet Oncol 16: e322-e332, 2015

33. von Baumgarten L, Illerhaus G, Korfel A, Schlegel U, Deckert M and Dreyling M: The diagnosis and treatment of primary CNS LYmphoma. Dtsch Arztebl Int 115: 419-426, 2018.

34. Antinori A, De Rossi G, Ammassari A, Cingolani A, Murri R, Di Giuda D, De Luca A, Pierconti F, Tartaglione T, Scerrati M, et al Value of combined approach with thallium-201 single-photon emission computed tomography and Epstein-Barr virus DNA polymerase chain reaction in CSF for the diagnosis of AIDS-related primary CNS lymphoma. J Clin Oncol 17: 554-560, 1999.

35. Sasagawa Y, Akai T, Tachibana O and Iizuka H: Diagnostic value of interleukin-10 in cerebrospinal fluid for diffuse large B-cell lymphoma of the central nervous system. J Neurooncol 121: $177-183,2015$.

36. Song Y, Zhang W, Zhang L, Wu W, Zhang Y, Han X, Yang C, Zhang L and Zhou D: Cerebrospinal fluid IL-10 and IL-10/IL-6 as accurate diagnostic biomarkers for primary central nervous system large B-cell lymphoma. Sci Rep 6: 38671, 2016.

37. Rubenstein JL, Wong VS, Kadoch C, Gao HX, Barajas R, Chen L, Josephson SA, Scott B, Douglas V, Maiti M, et al: CXCL13 plus interleukin 10 is highly specific for the diagnosis of CNS lymphoma. Blood 121: 4740-4748, 2013.

38. Viaccoz A, Ducray F, Tholance Y, Barcelos GK, Thomas-Maisonneuve L, Ghesquières H, Meyronet D, Quadrio I, Cartalat-Carel S, Louis-Tisserand G, et al: CSF neopterin level as a diagnostic marker in primary central nervous system lymphoma. Neuro Oncol 17: 1497-1503, 2015.

39. Caudie C, Bancel J, Dupont M, Matanza D, Poitevin F and Honnorat J: CSF levels and diagnostic utility of cerebrospinal fluid beta2-microglobulin. Ann Biol Clin (Paris) 63: 631-637, 2005.

40. Strehlow F, Bauer S, Martus P, Weller M, Roth P, Schlegel U, Seidel S, Scheibenbogen C, Korfel A and Kreher S: Osteopontin in cerebrospinal fluid as diagnostic biomarker for central nervous system lymphoma. J Neurooncol 129: 165-171, 2016.

41. Kersten MJ, Evers LM, Dellemijn PL, van den Berg H, Portegies P, Hintzen RQ, van Lier RA, von dem Borne AE and van Oers RH: Elevation of cerebrospinal fluid soluble CD27 levels in patients with meningeal localization of lymphoid malignancies. Blood 87: 1985-1989, 1996.
42. Baraniskin A, Kuhnhenn J, Schlegel U, Chan A, Deckert M, Gold R, Maghnouj A, Zöllner H, Reinacher-Schick A, Schmiegel W, et al: Identification of microRNAs in the cerebrospinal fluid as marker for primary diffuse large B-cell lymphoma of the central system. Blood 117: 3140-3146, 2011.

43. Zheng J, Xu J, Ma S, Sun X, Geng M and Wang L: Clinicopathological study of gene rearrangement and microRNA expression of primary central nervous system diffuse large B-cell lymphomas. Int J Clin Exp Pathol 6: 2048-2055, 2013.

44. Yu X, Li Z, Shen J, Chan MT and Wu WK: Role of microRNAs in primary central nervous system lymphomas. Cell Prolif 49: 147-153, 2016.

45. Rimelen V, Ahle G, Pencreach E, Zinniger N, Debliquis A, Zalmaï L, Harzallah I, Hurstel R, Alamome I, Lamy F, et al: Tumor cell-free DNA detection in CSF for primary CNS lymphoma diagnosis. Acta Neuropathol Commun 7: 43, 2019.

46. Thaler FS, Laurent SA, Huber M, Mulazzani M, Dreyling M, Ködel U, Kümpfel T, Straube A, Meinl E and von Baumgarten L: Soluble TACI and soluble BCMA as biomarkers in primary central nervous system lymphoma. Neuro Oncol 19: 1618-1627, 2017.

47. Ho KG and Grommes C: Molecular profiling of primary central nervous system lymphomas-predictive and prognostic value? Curr Opin Neurol 32: 886-894, 2019.

48. Deguchi S, Nakashima K, Muramatsu K, Mitsuya K, Oishi T, Shirata K, Hayashi N, Sugino T, Endo M and Nakasu Y: Pretreatment intratumoral susceptibility signals correlate with response to high-dose methotrexate and progression-free survival in primary central nervous system lymphoma. J Clin Neurosci 69: 43-50, 2019.

49. Phillips EH, Fox CP and Cwynarski K: Primary CNS lymphoma. Curr Hematol Malig Rep 9: 243-253, 2014.

50. Bataille B, Delwail V, Menet E, Vandermarcq P, Ingrand P, Wager M, Guy G and Lapierre F: Primary intracerebral malignant lymphoma: Report of 248 cases. J Neurosurg 92: 261-266, 2000.

51. Lim T, Kim SJ, Kim K, Lee JI, Lim DH, Lee DJ, Baek KK, Lee HY, Han B, Uhm JE, et al: Primary CNS lymphoma other than DLBCL: A descriptive analysis of clinical features and treatment outcomes. Ann Hematol 90: 1391-1398, 2011.

52. Van Der Meulen M, Dinmohamed AG, Visser O, Doorduijn JK and Bromberg JEC: Improved survival in primary central nervous system lymphoma up to age 70 only: A population-based study on incidence, primary treatment and survival in the Netherlands, 1989-2015. Leukemia 31: 1822-1825, 2017.

53. Fallah J, Qunaj L and Olszewski AJ: Therapy and outcomes of primary central nervous system lymphoma in the United States: Analysis of the national cancer database. Blood Adv 1: 112-121, 2016.

54. Graham MS and DeAngelis LM: Improving outcomes in primary CNS lymphoma. Best Pract Res Clin Haematol 31: 262-269, 2018

55. Glass J, Won M, Schultz CJ, Brat D, Bartlett NL, Suh JH, Werner-Wasik M, Fisher BJ, Liepman MK, Augspurger M, et al: Phase I and II study of induction chemotherapy with methotrexate, rituximab, and temozolomide, followed by whole-brain radiotherapy and postirradiation temozolomide for primary CNS lymphoma: NRG oncology RTOG 0227. J Clin Oncol 34: $1620-1625,2016$

56. Royer-Perron L and Hoang-Xuan K: Management of primary central nervous system lymphoma. Presse Med 47: e213-e244, 2018.

57. Kasenda B, Ferreri AJ, Marturano E, Forst D, Bromberg J, Ghesquieres H, Ferlay C, Blay JY, Hoang-Xuan K, Pulczynski EJ, et al: First-line treatment and outcome of elderly patients with primary central nervous system lymphoma (PCNSL)-a systematic review and individual patient data meta-analysis. Ann Oncol 26: 1305-1313, 2015.

58. Houillier C, Ghesquières H, Chabrot C, Soussain C, Ahle G, Choquet S, Nicolas-Virelizier E, Bay JO, Vargaftig J, Gaultier C, et al: Rituximab, methotrexate, procarbazine, vincristine and intensifified cytarabine consolidation for primary central nervous system lymphoma (PCNSL) in the elderly: A LOC network study. J Neurooncol 133: 315-320, 2017

59. Fritsch K, Kasenda B, Schorb E, Hau P, Bloehdorn J, Möhle R, Löw S, Binder M, Atta J, Keller U, et al: High-dose methotrexate-based immuno-chemotherapy for elderly primary CNS lymphoma patients (PRIMAIN study). Leukemia 31: 846-852, 2017. 
60. Hoang-Xuan K, Taillandier L, Chinot O, Soubeyran P, Bogdhan U, Hildebrand J, Frenay M, De Beule N, Delattre JY and Baron B; European Organization for Research and Treatment of Cancer Brain Tumor Group: Chemotherapy alone as initial treatment for primary CNS lymphoma in patients older than 60 years: A multicenter phase II study (26952) of the European organization for research and treatment of cancer brain tumor group. J Clin Oncol 21: 2726-2731, 2003.

61. Illerhaus G, Marks R, Müller F, Ihorst G, Feuerhake F, Deckert M, Ostertag $\mathrm{C}$ and Finke J: High-dose methotrexate combined with procarbazine and CCNU for primary CNS lymphoma in the elderly: Results of a prospective pilot and phase II study. Ann Oncol 20: 319-325, 2009.

62. Roth P, Martus P, Kiewe P, Möhle R, Klasen H, Rauch M, Röth A, Kaun S, Thiel E, Korfel A and Weller M: Outcome of elderly patients with primary CNS lymphoma in the G-PCNSL-SG-1 trial. Neurology 79: 890-896, 2012.

63. Olivier G, Clavert A, Lacotte-Thierry L, Gardembas M, Escoffre-Barbe M, Brion A, Cumin I,Legouffe E, Solal-Celigny P, Chabin M, et al: A phase 1 dose escalation study of idarubicin combined with methotrexate, vindesine, and prednisolone for untreated elderly patients with primary central nervous system lymphoma. The GOELAMS LCP 99 trial. Am J Hematol 89: 1024-1029, 2014.

64. Omuro A, Chinot O, Taillandier L, Ghesquieres H, Soussain C, Delwail V, Lamy T, Gressin R, Choquet S, Soubeyran P, et al: Methotrexate and temozolomide vs. methotrexate, procarbazine, vincristine, and cytarabine for primary CNS lymphoma in an elderly population: An intergroup ANOCEF-GOELAMS randomized phase 2 trial. Lancet Haematol 2: e251-e259, 2015.

65. Pulczynski EJ, Kuittinen O, Erlanso M, Hagberg H, Fosså A, Eriksson M, Nordstrøm M, Østenstad B, Fluge Ø, Leppä S, et al: Successful change of treatment strategy in elderly patients with primary central nervous system lymphoma by de-escalating induction and introducing temozolomide maintenance: Results from a phase II study by the Nordic Lymphoma Group. Haematologica 100: 534-540, 2015.

66. Mendez JS, Ostrom QT, Gittleman H, Kruchko C, DeAngelis LM, Barnholtz-Sloan JS and Grommes C: The elderly left behind-changes in survival trends of primary central nervous system lymphoma over the past 4 decades. Neuro Oncol 20: 687-694, 2018

67. Langner-Lemercier S, Houillier C, Soussain C, Ghesquières H, Chinot O, Taillandier L, Soubeyran P, Lamy T, Morschhauser F, Benouaich-Amiel A, et al: Primary CNS lymphoma at first relapse/progression: Characteristics, management, and outcome of 256 patients from The French LOC network. Neuro Oncol 18: 1297-1303, 2016

68. Jahnke K, Thiel E, Martus P, Herrlinger U, Weller M, Fischer L and Korfel A; German Primary Central Nervous System Lymphoma Study Group: Relapse of primary central nervous system lymphoma: Clinical features, outcome and prognostic factors. J Neurooncol 80: 159-165, 2006.

69. Nayak L, Hedvat C, Rosenblum MK, Abrey LE and DeAngelis LM: Late relapse in primary central nervous system lymphoma: Clonal persistence. Neuro Oncol 13: 525-529, 2011.

70. Abrey LE, Ben-Porat L, Panageas KS, Yahalom J, Berkey B, Curran W, Schultz C, Leibel S, Nelson D, Mehta M and DeAngelis LM: Primary central nervous system lymphoma: The memorial Sloan-kettering cancer Center prognostic model. J Clin Oncol 24: 5711-5715, 2006.

71. Ferreri AJ, Blay JY, Reni M, Pasini F, Spina M, Ambrosetti A, Calderoni A, Rossi A, Vavassori V, Conconi A, et al: Prognostic scoring system for primary CNS lymphomas: The International extranodal lymphoma study group experience. J Clin Oncol 21: 266-272, 2003

72. Weller M, Martus P, Roth P, Thiel E and Korfel A; German PCNSL Study Group: Surgery for primary CNS lymphoma? Challenging a paradigm. Neuro Oncol 14: 1481-1484, 2012.

73. Makino K, Nakamura H, Hide T, Kuroda J, Yano S and Kuratsu J: Prognostic impact of completion of initial high-dose methotrexate therapy on primary central nervous system lymphoma: A single institution experience. Int J Clin Oncol 20: 29-34, 2015

74. Nakasu Y, Mitsuya K, Hayashi N, Okamura I, Mori K, Enami T, Tatara R, Nakasu S and Ikeda T: Response-adapted treatment with upfront high-dose chemotherapy followed by autologous stem-cell transplantation rescue or consolidation phase high-dose methotrexate for primary central nervous system lymphoma: A long-term mono-center study. Springerplus 5: 307, 2016.
75. Kondo E, Ikeda T, Izutsu K, Chihara D, Shimizu-Koresawa R, Fujii N, Sakai T, Kondo T, Kubo K, Kato Y, et al: High dose chemotherapy with autologous stem cell transplantation in primary central nervous system lymphoma: Data from the Japan Society for Hematopoietic Cell Transplantation (JSHCT) registry. Biol Blood Marrow Transplant 25: 899-905, 2019.

76. Levy O, DeAngelis LM, Filippa DA, Panageas KS and Abrey LE: Bcl-6 predicts improved prognosis in primary central nervous system lymphoma. Cancer 112: 151-156, 2008.

77. Preusser M, Woehrer A, Koperek O, Rottenfusser A, Dieckmann K, Gatterbauer B, Roessler K, Slavc I, Jaeger U, Streubel B, et al: Primary central nervous system lymphoma: A clinicopathological study of 75 cases. Pathology 42: 547-552, 2010.

78. Niparuck P, Boonsakan $\mathrm{P}$, Sutthippingkiat T, Pukiat S, Chantrathammachart P, Phusanti S, Boonyawat K, Puavilai T, Angchaisuksiri P, Ungkanont A, et al: Treatment outcome and prognostic factors in PCNSL. Diagn Pathol 14: 56, 2019.

79. Chen C, Zhuo H, Wei X and Ma X: Contrast-enhanced MRI texture parameters as potential prognostic factors for primary central nervous system lymphoma patients receiving high-dose methotrexate-based chemotherapy. Contrast Media Mol Imaging 2019: 5481491, 2019

80. Alame M, Pirel M, Costes-Martineau V, Bauchet L, Fabbro M, Tourneret A, De Oliveira L, Durand L, Roger P, Gonzalez S, et al: Characterisation of tumour microenvironment and immune checkpoints in primary central nervous system diffuse large B cell lymphomas. Virchows Arch 476: 891-902, 2020.

81. Cho I, Lee H, Yoon SE, Ryu KJ, Ko YH, Kim WS and Kim SJ: Serum levels of soluble programmed death-ligand 1 (sPD-L1) in patients with primary central nervous system diffuse large B-cell lymphoma. BMC Cancer 20: 120, 2020.

82. Cambruzzi E: Primary intra-axial diffuse large b-cell lymphoma in immunocompetent patients: Clinical impact of molecular analysis and histogenetic evaluation. World Neurosurg 134: 215-220, 2020.

83. Yuan XG, Huang YR, Yu T, Xu Y, Liang Y, Zhang XH, Sun CR and Zhao XY: Primary central nervous system lymphoma in China: A single-center retrospective analysis of 167 cases. Ann Hematol 99: 93-104, 2020.

84. Tabouret E, Houillier C, Martin-Duverneuil N, Blonski M, Soussain C, Ghesquières H, Houot R, Larrieu D, Soubeyran P, Gressin R, et al: Patterns of response and relapse in primary CNS lymphomas after first-line chemotherapy: Imaging analysis of the ANOCEF-GOELAMS prospective randomized trial. Neuro Oncol 19: 422-429, 2017.

85. Chunsong H, Yuling H, Li W, Jie X, Gang Z, Qiuping Z, Qingping G, Kejian Z, Li Q, Chang AE, et al: CXC chemokine ligand 13 and $C C$ chemokine ligand 19 cooperatively render resistance to apoptosis in $\mathrm{B}$ cell lineage acute and chronic lymphocytic leukemia CD23+CD5+ B cells. J Immunol 177: 6713-6722, 2006.

86. Le M, Garcilazo Y, Ibáñez-Juliá MJ, Younan N, Royer-Perron L, Benazra M, Mokhtari K, Houillier C, Hoang-Xuan K and Alentorn A: Pretreatment hemoglobin as an independent prognostic factor in primary central nervous system lymphomas. Hematologic malignancies. Oncologist 24: e898-e904, 2019.

87. Oyama T, Yamamoto K, Asano N, Oshiro A, Suzuki R, Kagami Y, Morishima Y, Takeuchi K, Izumo T, Mori S, et al: Age-related EBV associated B-cell lymphoproliferative disorders constitute a distinct clinicopathologic group: A study of 96 patients. Clin Cancer Res 13: 5124-5132, 2007.

88. Wu T, Kang H, Zhuang D, Ma Y, Lin Z, Suolitiken D, Chen B and $\mathrm{Xu} \mathrm{X}$ : The role of $\mathrm{ABCB} 1$ polymorphism as a prognostic marker for primary central nervous system lymphoma. Ann Hematol 98: 923-930, 2019.

89. Yang X, Wang Y, Sun X, Bai X, Cui Q, Zhu H, Qian J, Chen Y, Sun S, Ji N, et al: STAT3 activation is associated with IL-10 expression and survival in primary central nervous system lymphoma. World Neurosurg 134: e1077-e1084, 2020.

90. Hatzl S, Posch F, Deutsch A, Beham-Schmid C, Stöger H, Greinix H, Pichler M, Neumeister P and Prochazka KT: Immunohistochemistry for c-myc and bcl-2 overexpression improves risk stratification in primary central nervous system lymphoma (PCNSL). Hematol Oncol 38: 277-283, 2020.

91. Yin W, Xia X, Wu M, Yang H, Zhu X, Sun W and Ge M: The impact of BCL-2/MYC protein expression and gene abnormality on primary central nervous system diffuse large B-cell lymphoma. Int J Clin Exp Pathol 12: 2215-2223, 2019. 
92. Villa D, Tan KL, Steidl C, Ben-Neriah S, Al Moosawi M, Shenkier TN, Connors JM, Sehn LH, Savage KJ, Scott DW, et al: Molecular features of a large cohort of primary central nervous system lymphoma using tissue microarray. Blood Adv 3: 3953-3961, 2019.

93. Takano S, Hattori K, Ishikawa E, Narita Y, Iwadate Y, Yamaguchi F, Nagane M, Akimoto J, Oka H, Tanaka S, et al: MyD88 mutation in elderly predicts poor prognosis in primary central nervous system lymphoma: Multi-institutional analysis. World Neurosurg 112: e69-e73, 2018.

94. Nayyar N, White MD, Gill CM, Lastrapes M, Bertalan M, Kaplan A, D'Andrea MR, Bihun I, Kaneb A, Dietrich J, et al: MYD88 L265P mutation and CDKN2A loss are early mutational events in primary central nervous system diffuse large B-cell lymphomas. Blood Adv 3: 375-383, 2019.

95. Mondello P, Cuzzocrea S, Arrigo C, Pitini V, Mian M and Bertoni F: STAT6 activation correlates with cerebrospinal fluid IL-4 and IL-10 and poor prognosis in Primary Central Nervous System Lymphoma. Hematol Oncol 38: 106-110, 2020.

96. Hyung J, Hong JY, Kim S, Ryu JS, Huh J and Suh C: Beta-2 microglobulin as a prognostic factor of primary central nervous system lymphoma. Blood Res 54: 285-288, 2019.

97. Kim S, Nam SJ, Park C, Kwon D, Yim J, Song SG, Ock CY, Kim YA, Park SH, Kim TM, et al: High tumoral PD-L1 expression and low PD-1 + or CD8 + tumor-infiltrating lymphocytes are predictive of a poor prognosis in primary diffuse large B-cell lymphoma of the central nervous system. Oncoimmunology 8: e1626653, 2019.

98. Gopal S, Martin KE, Richards KL and Eron JJ: Clinical presentation, treatment, and outcomes among 65 patients with HIV-associated lymphoma treated at the University of North Carolina, 2000-2010. AIDS Res Hum Retroviruses 28: 798-805, 2012.

99. Han $\mathrm{CH}$ and Batchelor TT: Diagnosis and management of primary central nervous system lymphoma. Cancer 123: 4314-4324, 2017.

100. Corry J, Smith JG, Wirth A, Quong G and Liew KH: Primary central nervous system lymphoma: Age and performance status are more important than treatment modality. Int J Radiat Oncol Biol Phys 41: 615-620, 1998.

101. Mohile SG, Dale W, Somerfield MR, Schonberg MA, Boyd CM, Burhenn PS, Canin B, Cohen HJ, Holmes HM, Hopkins JO, et al: Practical Assessment and Management of Vulnerabilities in Older Patients Receiving Chemotherapy: ASCO Guideline for Geriatric Oncology. J Clin Oncol 36: 2326-2347, 2018

102. Extermann M, Boler I, Reich RR, Lyman GH, Brown RH, DeFelice J, Levine RM, Lubiner ET, Reyes P, Schreiber FJ III and Balducci L: Predicting the risk of chemotherapy toxicity in older patients: The chemotherapy risk assessment scale for high-age patients (CRASH) score. Cancer 118: 3377-3386, 2012.

103. Hiraga S, Arita N, Ohnishi T, Kohmura E, Yamamoto K, Oku Y, Taki T, Sato M, Aozasa K and Yoshimine T: Rapid infusion of high-dose methotrexate resulting in enhanced penetration into cerebrospinal fluid and intensified tumor response in primary central nervous system lymphomas. J Neurosurg 91: 221-230, 1999.

104. Glass J, Shustik C, Hochberg FH, Cher L and Gruber ML: Therapy of primary central nervous system lymphoma with pre-irradiation methotrexate, cyclophosphamide, doxorubicin, vincristine, and dexamethasone (MCHOD). J Neurooncol 30: 257-265, 1996

105. Binnahil M, Au K, Lu JQ, Wheatley BM and Sankar T: The influence of Cortico-steroids on diagnostic accuracy of biopsy for primary central nervous system lymphoma. Can J Neurol Sci 43: 721-725, 2016.

106. Porter AB, Giannini C, Kaufmann T, Lucchinetti CF, Wu W, Decker PA, Atkinson JL and O'Neill BP: Primary central nervous system lymphoma can be histologically diagnosed after previous corticosteroid use: A pilot study to determine whether corticosteroids prevent the diagnosis of primary central nervous system lymphoma. Ann Neurol 63: 662-667, 2008.

107. Mathew BS, Carson KA and Grossman SA: Initial response to glucocorticoids: A potentially important prognostic factor in patients with primary CNS lymphoma. Cancer 106: 383-387, 2006.

108. Batchelor TT: Primary central nervous system lymphoma: A curable disease. Hematol Oncol 37 (Suppl 1): S15-S18, 2019.
109. Nabors LB, Portnow J, Baehring J, Brem H, Butowski N, Forsyth P, Hattangadi-Gluth J, Holdhoff M, Horbinski C, Howard S, et al: NCCN Clinical Practice Guidelines in Oncology. Central Nervous System Cancers 1: 32-35, 2018

110. Rushworth D, Mathews A, Alpert A and Cooper LJ: Dihydrofolate reductase and thymidylate synthase transgenes resistant to methotrexate interact to permit novel transgene regulation. J Biol Chem 290: 22970-22976, 2015.

111. Goecke IA, Alvarez C, Henríquez J, Salas K, Molina ML, Ferreira A and Gatica H: Methotrexate regulates the expression of glucocorticoid receptor alpha and beta isoforms in normal human peripheral mononuclear cells and human lymphocyte cell lines in vitro. Mol Immunol 44: 2115-2123, 2007.

112. Madle M, Krämer I, Lehners N, Schwarzbich M, Wuchter P, Herfarth K, Egerer G, Ho AD and Witzens-Harig M: The influence of rituximab, high-dose therapy followed by autologous stem cell transplantation, and age in patients with primary CNS lymphoma. Ann Hematol 94: 1853-1857, 2015.

113. Rubenstein JL, Hsi ED, Johnson JL, Jung SH, Nakashima MO, Grant B, Cheson BD and Kaplan LD: Intensive chemotherapy and immunotherapy in patients with newly diagnosed primary CNS lymphoma: CALGB 50202 (Alliance 50202). J Clin Oncol 31: 3061-3068, 2013

114. Jahnke K, Korfel A, Martus P, Weller M, Herrlinger U, Schmittel A, Fischer L and Thiel E; German Primary Central Nervous System Lymphoma Study Group (G-PCNSL-SG): High-dose methotrexate toxicity in elderly patients with primary central nervous system lymphoma. Ann Oncol 16: 445-449, 2005.

115. Welch MR, Omuro A and Deangelis LM: Outcomes of the oldest patients with primary CNS lymphoma treated at Memorial Sloan-Kettering Cancer Center. Neuro Oncol 14: 1304-1311, 2012.

116. Illerhaus G, Schorb E and Kasenda B: Novel agents for primary central nervous system lymphoma: Evidence and perspectives Blood 132: 681-688, 2018.

117. Faivre G, Butler MJ, Le I and Brenner A: Temozolomide as a single agent maintenance therapy in elderly patients with primary CNS lymphoma. Clin Lymphoma Myeloma Leuk 19: 665-669, 2019.

118. Shih C, Chen VJ, Gossett LS, Gates SB, MacKellar WC, Habeck LL, Shackelford KA, Mendelsohn LG, Soose DJ, Patel VF, et al: LY231514, a pyrrolo[2,3-d] pyrimidine-based antifolate that inhibits multiple folate-requiring enzymes. Cancer Res 57: 1116-1123, 1997.

119. Raizer JJ, Rademaker A, Evens AM, Rice L, Schwartz M, Chandler JP, Getch CC, Tellez C and Grimm SA: Pemetrexed in the treatment of relapsed/refractory primary central nervous system lymphoma. Cancer 118: 3743-3748, 2012.

120. Han S, Wang M, Liu B and Yu J: Pemetrexed for primary central nervous system lymphoma in the elderly. Clin Transl Oncol 18: 138-143, 2016

121. Pardridge WM: BBB-genomics: Creating new openings for brain-drug targeting. Drug Discovery Today 6: 381-383, 2001.

122. Thiel E, Korfel A, Martus P, Kanz L, Griesinger F, Rauch M, Röth A, Hertenstein B, von Toll T, Hundsberger T, et al: High-dose methotrexate with or without whole brain radiotherapy for primary CNS lymphoma (G-PCNSL-SG-1): A phase 3, randomised, non-inferiority trial. Lancet Oncol 11: 1036-1047, 2010.

123. Birnbaum T, Stadler EA, von Baumgarten L and Straube A: Rituximab significantly improves complete response rate in patients with primary CNS lymphoma. J Neurooncol 109: 285-291, 2012

124. Holdhoff M, Ambady P, Abdelaziz A, Sarai G, Bonekamp D, Blakeley J, Grossman SA and Ye X: High-dose methotrexate with or without rituximab in newly diagnosed primary CNS lymphoma. Neurology 83: 235-239, 2014.

125. Miyakita Y, Ohno M, Takahashi M, Muragaki Y, Katai H and Narita Y: Immunochemotherapy using rituximab (RTX) and high-dose methotrexate (HD-MTX): An evaluation of the addition of RTX to HD-MTX in recurrent primary central nervous system lymphoma (PCNSL). Jpn J Clin Oncol 47: 919-924, 2017.

126. Fritsch K, Kasenda B, Hader C, Nikkhah G, Prinz M, Haug V, Haug S, Ihorst G, Finke J and Illerhaus G: Immunochemotherapy with rituximab, methotrexate, procarbazine, and lomustine for primary CNS lymphoma (PCNSL) in the elderly. Ann Oncol 22: 2080-2085, 2011. 
127. Iwamoto FM, Schwartz J, Pandit-Taskar N, Peak S, Divgi CR, Zelenetz AD, Humm J and Abrey LE: Study of radiolabeled indium-111 and yttrium-90 ibritumomab tiuxetan in primary central nervous system lymphoma. Cancer 110: 2528-2534, 2007.

128. Ferreri AJ, Cwynarski K, Pulczynski E, Ponzoni M, Deckert M, Politi LS, Torri V, Fox CP, Rosée PL, Schorb E, et al: Chemoimmunotherapy with methotrexate, cytarabine, thiotepa, and rituximab (MATRix regimen) in patients with primary CNS lymphoma: Results of the first randomisation of the International Extranodal Lymphoma Study Group-32 (IELSG32) phase 2 trial. Lancet Haematol 3: e217-e227, 2016.

129. Schmitt AM, Herbrand AK, Fox CP, Bakunina K, Bromberg JEC, Cwynarski K, Doorduijn JK, Ferreri AJM, Illerhaus G, Issa S, et al: Rituximab in primary central nervous system lymphoma-a systematic review and Meta-analysis. Hematol Oncol 37: 548-557, 2019.

130. Bromberg JEC, Issa S, Bakunina K, Minnema MC, Seute T, Durian M, Cull G, Schouten HC, Stevens WBC,Zijlstra JM, et al: Rituximab in patients with primary CNS lymphoma (HOVON 105/ALLG NHL 24): A randomised, open-label, phase 3 intergroup Study. Lancet Oncol 20: 216-228, 2019.

131. Han X, Ji Y, Ouyang M, Zhu T and Zhou D: Efficacy and safety of HD-MTX based systemic chemotherapy regimens: Retrospective study of induction therapy for primary central nervous system lymphoma in Chinese. Sci Rep 7: 17053 , 2017.

132. Poortmans PM, Kluin-Nelemans HC, Haaxma-Reiche H, Van't Veer M, Hansen M, Soubeyran P, Taphoorn M, Thomas J, Van den Bent M, Fickers M, et al: High-dose methotrexate-based chemotherapy followed by consolidating radiotherapy in non-AIDS-related primary central nervous system lymphoma: European organization for research and treatment of cancer lymphoma group phase II trial 20962. J Clin Oncol 21: 4483-4488, 2003 .

133. van Tellingen O, Boogerd W, Nooijen WJ and Beijnen JH: The vascular compartment hampers accurate determination of teniposide penetration into braintumor tissue. Cancer Chemother Pharmacol 40: 330-334, 1997.

134. Wu J, Duan L, Zhang L, Sun Z, Fu X, Li X, Li L, Wang X, Zhang X, Li Z, et al: Fotemustine, teniposide and dexamethasone versus high-dose methotrexate plus cytarabine in newly diagnosed primary CNS lymphoma: A randomised phase 2 trial. J Neurooncol 140: 427-434, 2018.

135. Wang YX, Huang Y, Xu XP, Chen BB, Lin ZG, Ma Y, Ding TL and Wang Q: Curative effect of methotrexate combined with teniposide in the treatment of primary central nervous system lymphoma. Oncol Lett 19: 2097-2106, 2020.

136. Deng X, Xu X, Lin D, Zhang X, Yu L, Sheng H, Yin B, Zhang N and Lin J: Real-world impact of surgical excision on overall survival in primary central nervous system lymphoma. Front Oncol 10: 131, 2020

137. Kinslow CJ,Rae AI, Neugut AI, Adams CM, Cheng SK, Sheth SA, McKhann GM, Sisti MB, Bruce JN, Iwamoto FM, et al: Surgery plus adjuvant radiotherapy for primary central nervous system lymphoma. Br J Neurosurg 34: 690-696, 2020.

138. Korfel A and Schlegel U: Diagnosis and treatment of primary CNS lymphoma. Nat Rev Neurol 9: 317-327, 2013.

139. Schlegel U and Korfel A: Is whole-brain radiotherapy still a standard treatment for primary central nervous system lymphomas? Curr Opin Neurol 31: 733-739, 2018.

140. Shah GD, Yahalom J, Correa DD, Lai RK, Raizer JJ, Schiff D, LaRocca R, Grant B, DeAngelis LM and Abrey LE: Combined immunochemotherapy with reduced whole-brain radiotherapy for newly diagnosed primary CNS lymphoma. J Clin Oncol 25: 4730-4735, 2007.

141. Lee TH, Lee JH, Chang JH, Ye SJ, Kim TM, Park CK, Kim IH, $\mathrm{Kim} \mathrm{BH}$ and Wee CW: Reduced-dose whole-brain radiotherapy with tumor bed boost after upfront high-dose methotrexate for primary central nervous system lymphoma. Radiat Oncol J 38: 35-43, 2020

142. Gaut D and Schiller GJ: Hematopoietic stem cell transplantation in primary central nervous system lymphoma: A review of the literature. Int J Hematol 109: 260-277, 2019.

143. Schorb E, Fox CP, Fritsch K, Isbell L, Neubauer A, Tzalavras A, Witherall R, Choquet S, Kuittinen O, De-Silva D, et al: High-dose thiotepa-based chemotherapy with autologous stem cell support in elderly patients with primary central nervous system lymphoma: A European retrospective study. Bone Marrow Transplant 52: 1113-1119, 2017.
144. Vu K, Mannis G, Hwang J, Geng H and Rubenstein JL: Low-dose lenalidomide maintenance after induction therapy in older patients with primary central nervous system lymphoma. Br J Haematol 186: 180-183, 2019.

145. Bairey O and Siegal T: The possible role of maintenance treatment for primary central nervous system lymphoma. Blood Rev 32: 378-386, 2018.

146. Reni M and Ferreri AJ: Therapeutic management of refractory or relapsed primary central nervous system lymphomas. Ann Hematol 80 (Suppl 3): B113-B117, 2001.

147. Otani R, Yamada R, Kushihara Y, Inazuka M and Shinoura N: Continuous intrathecal injection therapy of methotrexate is a therapeutic option in primary CNS lymphoma. J Clin Neurosci 69: 26-30, 2019.

148. Soussain C, Suzan F, Hoang-Xuan K, Cassoux N, Levy V, Azar N, Belanger C, Achour E, Ribrag V, Gerber S, et al: Results of intensive chemotherapy followed by hematopoietic stem-cell rescue in 22 patients with refractory or recurrent primary CNS lymphoma or intraocular lymphoma. J Clin Oncol 19: 742-749, 2001.

149. Correa DD, Braun E, Kryza-Lacombe M, Ho KW Reiner AS, Panageas KS, Yahalom J, Sauter CS, Abrey LE, DeAngelis LM, et al: Longitudinal cognitive assessment in patients with primary CNS lymphoma treated with induction chemotherapy followed by reduced-dose whole-brain radiotherapy or autologous stem cell transplantation. J Neurooncol 144: 553-562, 2019.

150. Atilla E, Sahin U, Atilla PA, Merter M, Ozyurek E, Ceyhan K and Bozdag SC: Allogeneic stem cell transplantation for relapsed primary central nervous system lymphoma: Is it feasible? Hematol Oncol Stem Cell Ther 12: 220-225, 2019.

151. Varadi G, Or R, Kapelushnik J, Naparstek E, Nagler A, Brautbar C, Amar A, Kirschbaum M, Samuel S, Slavin S and Siegal T: Graft-versus-lymphoma effect after allogeneic peripheral blood stem cell transplantation for primary central nervous system lymphoma. Leuk Lymphoma 34: 185-190, 1999.

152. Tu S, Zhou X, Guo Z, Huang R, Yue C, He Y, Li M, Chen Y, Liu Y, Chang LJ and Li Y: CD19 and CD70 Dual-target chimeric antigen receptor T-cell therapy for the treatment of relapsed and refractory primary central nervous system diffuse large B-cell lymphoma. Front Oncol 9: 1350, 2019.

153. Lionakis MS, Dunleavy K, Roschewski M, Widemann BC, Butman JA, Schmitz R, Yang Y, Cole DE, Melani C, Higham CS, et al: Inhibition of B cell receptor signaling by Ibrutinib in primary CNS lymphoma. Cancer Cell 31: 833-843. e5, 2017.

154. Narita Y,Nagane M,MishimaK, Terui Y,Arakawa Y, YonezawaH, Asai K, Fukuhara N, Sugiyama K, Shinojima N, et al: Phase $1 / 2$ study of tirabrutinib, a second-generation Bruton's tyrosine kinase inhibitor, in relapsed/refractory primary central nervous system lymphoma. Neuro Oncol: noaa145, 2020 doi: 10.1093/neuonc/noaa145 (Epub ahead of print).

155. Tun HW, Johnston PB, DeAngelis LM, Atherton PJ, Pederson LD, Koenig PA, Reeder CB, Omuro AMP, Schiff D, O'Neill B, et al: Phase I study of pomalidomide and dexamethasone for relapsed/refractory primary CNS or vitreoretinal lymphoma. Blood 132: 2240-2248, 2018.

156. Nayak L, Iwamoto FM, LaCasce A, Mukundan S, Roemer MGM, Chapuy B, Armand P, Rodig SJ and Shipp MA: PD-1 blockade with nivolumab in relapsed/refractory primary central nervous system and testicular lymphoma. Blood 129: 3071-3073, 2017.

157. Ferry JA: The diversity of diffuse large B-cell lymphoma in extranodal sites: Overview and update. J Hematopathol 7: 57-70, 2014.

158. Chamoun K, Choquet S, Boyle E, Houillier C, Larrieu-Ciron D, Al Jijakli A, Delrieu V, Delwail V, Morschhauser F, Hoang-Xuan K and Soussain C: Ibrutinib monotherapy in relapsed/refractory CNS lymphoma: A retrospective case series. Neurology 88: 101-102, 2017.

159. Grommes C, Pastore A, Palaskas N, Tang SS, Campos C Schartz D, Codega P, Nichol D, Clark O, Hsieh WY, et al: IbrutInib unmasks critical role of Bruton tyrosine kinase in primary CNS lymphoma. Cancer Discov 7: 1018-1029, 2017.

160. Soussain C, Choquet S, Blonski M, Leclercq D, Houillier C, Rezai K, Bijou F, Houot R, Boyle E, Gressin R, et al: Ibrutinib monotherapy for relapse or refractory primary CNS lymphoma and primary vitreoretinal lymphoma: Final analysis of the phase II 'proof-of-concept' iLOC study by the Lymphoma study association (LYSA) and the French oculo-cerebral lymphoma (LOC) network. Eur J Cancer 117: 121-130, 2019. 
161. Yang Y, Shaffer AL III, Emre NC, Ceribelli M, Zhang M, Wright G, Xiao W, Powell J, Platig J, Kohlhammer H, et al: Exploiting synthetic lethality for the therapy of $\mathrm{ABC}$ diffuse large B cell lymphoma. Cancer Cell 21: 723-737, 2012.

162. Houillier C, Choquet S, Touitou V, Martin-Duverneuil N, Navarro S, Mokhtari K, Soussain C and Hoang-Xuan K: Lenalidomide monotherapy as salvage treatment for recurrent primary CNS lymphoma. Neurology 84: 325-326, 2015.

163. Rubenstein JL, Geng H, Fraser EJ, Formaker P, Chen L, Sharma J, Killea P, Choi K, Ventura J, Kurhanewicz J, et al: Phase 1 investigation of lenalidomide/rituximab plus outcomes of lenalidomide maintenance in relapsed CNS lymphoma. Blood Adv 2: 1595-1607, 2018

164. Ghesquieres H, Chevrier M, Laadhari M, Chinot O, Choquet S, Moluçon-Chabrot C, Beauchesne P, Gressin R, Morschhauser F, Schmitt A, et al: Lenalidomide in combination with intravenous rituximab (REVRI) in relapsed/refractory primary CNS lymphoma or primary intraocular lymphoma: A multicenter prospective 'proof of concept' phase II study of the French Oculo-Cerebral lymphoma (LOC) Network and the Lymphoma Study Association (LYSA). Ann Oncol 30: 621-628, 2019.

165. Takashima Y, Sasaki Y, Hayano A, Homma J, Fukai J, Iwadate Y, Kajiwara K, Ishizawa S, Hondoh H, Tokino T and Yamanaka R: Target amplicon exome-sequencing identifies promising diagnosis and prognostic markers involved in RTK-RAS and PI3K-AKT signaling as central oncopathways in primary central nervous system lymphoma. Oncotarget 9: 27471-27486, 2018.

166. Todorovic Balint M, Jelicic J, Mihaljevic B, Kostic J, Stanic B, Balint B, Pejanovic N, Lucic B, Tosic N, Marjanovic I, et al: Gene mutation profiles in primary diffuse large B cell lymphoma of central nervous system: Next generation sequencing analyses. Int J Mol Sci 17: 683, 2016.

167. Zhang X and Liu Y: Targeting the the PI3K/AKT/mTOR signaling pathway in primary central nervous system lymphoma: Current status and future prospects. CNS Neurol Disord Drug Targets 19: 165-173, 2020.
168. Korfel A, Schlegel U, Herrlinger U, Dreyling M, Schmidt C, von Baumgarten L, Pezzutto A, Grobosch T, Kebir S, ThielE, etal: Phase II trial of temsirolimus for Relapsed/Refractory primary CNS lymphoma. J Clin Oncol 34: 1757-1763, 2016.

169. Grommes C, Pentsova E, Nolan C, Wolfe J, Mellinghoff IK and Deangelis L: Phase II study of single agent buparlisib in recurrent/refractory primary (PCNSL) and secondary CNS lymphoma (SCNSL). Ann Oncol 27 (Suppl 6): vi103-vi113, 2016.

170. Ezell SA, Mayo M, Bihani T, Tepsuporn S, Wang S, Passino M, Grosskurth SE, Collins M, Parmentier J, Reimer C, et al: Synergistic induction of apoptosis by combination of BTK and dual mTORC1/2 inhibitors in diffuse large B cell lymphoma. Oncotarget 5: 4990-5001, 2014.

171. Tarantelli C, Gaudio E, Arribas AJ, Kwee I, Hillmann P, Rinaldi A, Cascione L, Spriano F, Bernasconi E, Guidetti F, et al: $\mathrm{PQR} 309$ is a novel dual PI3K/mTOR inhibitor with preclinical antitumor activity in lymphomas as a single agent and in combination therapy. Clin Cancer Res 24: 120-129, 2018.

172. Furuse M, Nonoguchi N, Omura N, Shirahata M, Iwasaki K, Inui T, Kuroiwa T, Kuwabara H and Miyatake SI: Immunotherapy of Nivolumab with dendritic cell vaccination is effective against intractable recurrent primary central nervous system lymphoma: A case report. Neurol Med Chir (Tokyo) 57: 191-197, 2017.

173. Chan TSY, Khong PL, Au-Yeung R, Kwong YL and Tse E: Low-dose nivolumab induced durable complete response in relapsed primary central nervous system diffuse large B cell lymphoma. Ann Hematol 98: 2227-2230, 2019.

This work is licensed under a Creative Commons Attribution-NonCommercial-NoDerivatives 4.0 International (CC BY-NC-ND 4.0) License. 